\title{
PROPRIEDADE ANTI-INFLAMATÓRIA DE KALANCHOE PINNATA PODE ESTAR ASSOCIADA À INIBIÇÃO NITRÉRGICA
}

\section{DISSERTAÇÃO}

MIRANDA, Adriele Mayara Soares 1, OLIVEIRA, Leonia da Conceição de 2, SANTOS, Cleidison da Silva ${ }^{3}$, MIRANDA, Igor de Sousa ${ }^{4}$

MIRANDA, Adriele Mayara Soares. Et al. Propriedade anti-inflamatória de Kalanchoe pinnata pode estar associada à inibição nitrérgica. Revista Científica Multidisciplinar Núcleo do Conhecimento. Ano 06, Ed. 05, Vol. 09, pp. 37-76. Maio de 2021. ISSN: 2448-0959, Link de acesso: https://www.nucleodoconhecimento.com.br/quimica/anti-inflamatoria, DOI: 10.32749/nucleodoconhecimento.com.br/quimica/anti-inflamatoria

\section{RESUMO}

Uma das plantas que tem sido muito utilizada como medicamento popular é a Kalanchoe pinnata (Lam.) Persson (Crassulaceae). Uma das primícias de seu uso é no tratamento de inflamações, infecções, feridas, ulcerações e gastrite. O objetivo do presente estudo foi identificar e quantificar constituintes bioativos e também avaliar as atividades antioxidante e anti-inflamatória tópica das folhas de $K$. pinnata. Pelo material seco e macerado com metanol, foi possível obter três frações: Hexânica; diclorometânica e acetato de etila. Os constituintes das frações e do extrato metanólico foram detectados por uma cromatografia líquida de alta capacidade

\footnotetext{
${ }^{1}$ Mestrado em Biociências pela Universidade Federal do Oeste do Pará.

${ }^{2}$ Mestrado em Biociências pela Universidade Federal do Oeste do Pará.

${ }^{3}$ Doutorando em Educação: Universidade Nacional de Rosário.

${ }^{4}$ Mestrado em Química pela Universidade Federal do Pará.
}

RC: 85294

Disponível em: https://www.nucleodoconhecimento.com.br/quimica/anti-inflamatoria 
acoplada a detector de ultravioleta e cromatografia com fase gasosa acoplada à espectrometria de massas. Esse efeito anti-inflamatório foi analisado pelo modelo de bolsa de ar induzido por carragenina conforme Vinegar et al. (1973). Nesse estudo fitoquímico, foi possível identificar a presença de taninos, flavonoides e glicosídeos cardiotônicos. Na bolsa de ar, a dose de $400 \mathrm{mg} / \mathrm{kg}$ foi verificada, possibilitando e gerando a significativa redução de volume do exsudato inflamatório, comparada com o controle, porém, não conseguindo inibir a migração leucocitária. O grupo tratado com dexametasona apenas reduziu o volume de exsudato. Sendo assim, os resultados indicam que a planta Kalanchoe pinnata pode ser uma fonte de novos compostos químicos com atividades anti-inflamatórios.

Palavras-chave: Kalanchoe pinnata, Flavonoides, Estudo Fitoquímico, Atividade Anti-inflamatória.

\section{INTRODUÇÃO}

Muitos grupos éticos ou comunidades pobres, só tem como unico recurso o conhecimento de plantas consideradas como medicinais, tais plantas tem sido utilizados na cura e no tratamento de enfermidades durante milênios na espécie humana (MUTHU et al., 2006). Os produtos naturais faziam parte dos antigos sistemas de medicina tradicional, por exemplo, chinesa e egípcia (SARKER, 2016).

Ainda hoje, as plantas medicinais são amplamente utilizadas em diversos países, alguns desses conhecidos como industrializados, tais como: Canadá, França, Alemanha e Itália. Estima-se que entre $70 \%$ a $90 \%$ da população desses países, utiliza as plantas medicinais com o título de "complementar", "alternativo" ou "não convencional" (ROBINSON e ZANGHE, 2011).

O tratamento de doenças com uso de plantas medicinais, baseado no conhecimento comum e popular o qual foi acumulado com o passar do tempo e transmitida para

RC: 85294

Disponível em: https://www.nucleodoconhecimento.com.br/quimica/anti-inflamatoria 
posteriores gerações, constitui a Medicina Tradicional (MUTHUIRULAPPAN; RAJENDREN, 2013). De acordo com Organização Mundial da Saúde (OMS), cerca de 3,4 bilhões de pessoas nos países em desenvolvimento usam remédios tradicionais à base de plantas. Isso por volta de $88 \%$ da população mundial, que usa principalmente a medicina tradicional na atenção primaria à saúde (BRASIL, 2006; SOUSA et al., 2008). Este ramo do conhecimento deu origem a Fitoterapia que é definida como a prática do uso de plantas ou suas partes com finalidade terapêutica (FELTROW; AVILA, 2000).

No Brasil não é diferente, nas regiões mais pobres e mesmo nas grandes cidades brasileiras, plantas medicinais são comercializadas em feiras livres, mercados populares ou encontradas em quintais de residências. As observações da eficácia do uso de plantas medicinais no tratamento de doenças contribuem para divulgação da eficiência e eficácia das plantas denominadas de medicinais, apesar de não terem seus constituintes químicos conhecidos. Dessa forma, os usuários que utilizam este tipo de cultura medicinal despertam o interesse de pesquisadores em estudos envolvendo áreas, como por exemplo, botânica, farmacologia e fitoquímica, ampliando o conhecimento sobre fonte medicinal natural (MACIEL et al, 2002).

Estima-se que aproximadamente $61 \%$ das 877 novas entidades químicas de pequenas moléculas introduzidas como fármacos no mundo entre 1981 e 2002 podem ser remontadas a produtos naturais, ou foram desenvolvidas a partir deles. Elas incluem produtos naturais $(6 \%)$, derivados de produtos naturais $(27 \%)$, compostos sintéticos com fármacos derivados de produtos naturais (5\%) e compostos sintéticos planejados com base no conhecimento obtido a partir do produto natural, isto é, imitação de produto natural (23\%). Em algumas áreas terapêuticas, a contribuição dos produtos naturais ainda é maior, por exemplo, cerca de $78 \%$ dos antibacterianos e $74 \%$ dos candidatos a fármacos antineoplásicos malignos são de produtos naturais ou análogos estruturais de produtos naturais (MACIEL et al, 2002).

RC: 85294

Disponível em: https://www.nucleodoconhecimento.com.br/quimica/anti-inflamatoria 
O conhecimento dos mecanismos envolvidos nos processos inflamatórios promoveu também o desenvolvimento de terapias anti-inflamatórias e diversos agentes terapêuticos estão disponíveis para o tratamento. Os fármacos anti-inflamatórios estão entre os mais utilizados pela medicina moderna e alguns tiveram origem de produtos naturais ou (semi) sintéticos, como o ácido acetilsalicílico (A.A.S.), um AINE, proveniente do ácido salicílico obtido de Salix spp (SILVA; CARVALHO, 2004).

Para dar um início sobre esse estudo de plantas medicinais, os pesquisadores podem levar em consideração as seguintes abordagens: etnobotânica e/ou quimiossistemática e/ou ao acaso (ALBUQUERQUE; HANAZAKI, 2006). Geralmente, a abordagem etnobotânica que tem como principal motivo, avaliar e caracterizar, visando aspectos químicos e farmacológicos das plantas, tem sido utilizado para fundamentar os usos tradicionais. Por exemplo, Okwu e Nnamdi (2011), partindo do uso popular de Kalanchoe pinnata (Crassulaceae) no processo desse tratamento de infecções em feridas, foi feito o isolamento de dois flavonoides do extrato etanólico de folhas com atividade antimicrobiana, revelando o popular uso da espécie e criando perspectivas para 0 alcance de novos fármacos e medicamentos. Ainda Afzal e colaboradores (2012) isolaram cinco substâncias das folhas de Kalanchoe pinnata (sinônimo Bryophyllom pinnatum), sendo o derivado esteroidal estigmast-4,20(21),23-trien-3-ona inédito. Essa substância (300 mg/kg) e o extrato aquoso $(400 \mathrm{mg} / \mathrm{kg})$ demonstraram atividade anti-inflamatória em modelo de inflamação

Kalanchoe pinnata pertence à família Crassulaceae. A família é composta pelo gênero Kalanchoe que compreende aproximadamente 125 espécies muitas delas nativas da África (COSTA et al., 2008; EL ABDELLAOUl et al., 2010). Tem como sinônimos os nomes científicos Sinonimos: Bryophyllum calycinum, B. germinans, $B$. pinnatum, Cotyledon calycina, C. calyculata, C. pinnata, C. rhizophilla, Crassuvia froripendia, Crassula pinnata, Sedum madagascariense, Verea pinnata, é conhecida RC: 85294

Disponível em: https://www.nucleodoconhecimento.com.br/quimica/anti-inflamatoria 
popularmente na região norte como: coirama, coirama branca, diabinho e em outras regiões do país como: Erva-da-costa, folha-da-costa, folha-da-fortuna, folha-grossa, e orelha-de-monge (MAJAZ et al., 2011). Muitas comunidades já utilizam o extrato das folhas da Kalanchoe em forma de chá para tratamento de doenças gástricas, dores no corpo, doenças inflamatórias, entre outras (ALMEIDA et al., 2000; KAMBOJ e SALUJA, 2009; OKWU; JOSIAH, 2006).

Encontramos, na literatura, vários estudos os quais tem confirmado vários potenciais relacionados com a Kalanchoe pinnata. Por exemplo, Afzal et al. (2012) e também Gupta et al (2010) observaram em seus estudos um potencial anti-inflamatório e analgésico relacionado ao estudo do extrato da Kalanchoe pinnata. Ainda Muzitano e colaboradores (2006) verificaram atividades anti-leishmanicida relacionado a esta planta. Outros estudos ainda comprovaram atividades antidiabética (OJEWOLE, 2005), antibactericida (BISWAS et al., 2011), antimicrobiana (AKINPELU et al., 2000) e antialérgica (CRUZ et al., 2012). Observa-se também, estudos que citam o potencial anticancerígeno, neurológica (sedativa e relaxante muscular), hipoglicemiante e hipolipidêmica (SALAHDEEN; YEMIATAN, 2006).

Mesmo com vários estudos relacionados ao potencial farmacológico da Kalanchoe pinnata em análises fitoquímicas realizadas por diversos autores por meio de extratos e frações isoladas dessa planta, ainda é possível observar cada vez mais novas substâncias com potenciais diversos e atividades anti-inflamatórias (AFZAL et al., 2012; CHOI et al., 2012; TATSIMO et al., 2012; OKWU; NNAMDI, 2011; OTUKI; JOSIAH, 2006).

Com relação às folhas de $K$. pinnata já foi relatada a presença majoritária de flavonoides (livres e glicosilados), saponinas e alcaloides, sendo os flavonoides a principal classe química do gênero Kalanchoe (CRUZ et al., 2011; OKWU; JOSIAH, 2006). Muzitano e colaboradores (2011) avaliaram a influência das condições de cultivo, estação do ano e método de extração sobre a concentração de flavonoides 
encontrada em extratos aquosos de $K$. pinnata e demonstraram que o flavonoídico é um conteúdo potencializado quando a planta é exposta sob a maior exposição da luz solar e quando coletada nos períodos do ano em que ocorre há maior existência de radiação solar, como o verão e a primavera.

Os modelos de inflamação in vivo, como edema de pata, de orelha, bolsa de ar, induzido por agentes flogísticos e pleurisia têm sido utilizados frequentemente nos estudos de atividade anti-inflamatória com produtos naturais e sintéticos (WILLOUGHBY, 2003). Porém algumas técnicas possuem limitações como as dificuldades de manipulação no decorrer da inflamação, indução e a determinação da quantidade de parâmetros inflamatórios (edema, número e tipo de células envolvidas, extravasamento de proteínas, mediadores envolvidos). Dentre os agentes flogísticos que podem ser utilizados destaca-se a carragenina, obtido de algas marinhas. Este agente produz uma resposta inflamatória aguda no modelo da pleurisia em camundongos (SEDGWICK e WILLOUGHBY, 1985).

O modelo da bolsa de ar tem seus primeiros relatos em ratos na década de 60 (OKUDAIRA e SCHUWARZ, 1962) e em camundongos nos anos 70. Neste modelo, a partir do lavado da bolsa de ar, é viável a avaliação do extravasamento de líquido, a migração de células bem como a mensuração de enzimas como a ciclooxigenase e outros mediadores como óxido nítrico, prostaglandinas e leucotrienos, induzidos por diversos agentes flogísticos (POSADAS et al., 2000).

A técnica do modelo da bolsa de ar possuem vantagem em relação a outras técnicas encontradas na literatura, pois a partir da coleta dos lavados da cavidade pleural e da bolsa de ar é possível analisar e quantificar diversos parâmetros inflamatórios como "celularidade, exsudação, mediadores inflamatórios (citocinas, óxido nítrico, entre outros), além da participação de enzimas como mieloperoxidase e adenosinadeaminase". (SOARES, 2017 p. 31) Sem a necessidade de recorrer a procedimentos complicados de extração e quantificação.

RC: 85294

Disponível em: https://www.nucleodoconhecimento.com.br/quimica/anti-inflamatoria 
Diante do exposto, esse trabalho demonstra buscar o significativo potencial desta planta (Kalanchoe pinnata) em atividades farmacológicas, possibilitando assim a seleção de fármacos/plantas com potencial atividade anti-inflamatória para o modelo de bolsa ar (SEDGWICK e WILLOUGHBY, 1985). Desta forma, o estudo objetiva contribuir na busca de uma nova medicação terapêutica para o tratamento de inflamações, tal busca foi efetuada pela investigação da espécie vegetal $K$. pinnata. Para tanto, foram investigadas as atividades anti-inflamatórias (modelo de bolsa de ar) bem como a identificação de compostos presentes na planta em estudo, sugerindo uma possível relação destes com a referida atividade farmacológica.

\section{PARTE EXPERIMENTAL}

\subsection{AVALIAÇÃO DE ATIVIDADE ANTI-INFLAMATÓRIA EM MODELO DE BOLSA DE AR}

\subsubsection{ANIMAIS}

Foram utilizados Rattus norvegicus da linhagem Wistar (180-200 g), machos, com 45 dias de idade, provenientes do Biotério UFOPA- campus Oriximiná. Os animais foram mantidos em gaiolas plásticas com ração e água ad libitum a temperatura ambiente $\left(22-25^{\circ} \mathrm{C}\right)$. Os protocolos utilizados foram aprovados pelo Comitê de Ética na Experimentação Animal (CEUA) da Universidade Federal do Oeste do Pará (protocolo no 105/2012).

\subsubsection{FÁRMACOS}

Os fármacos usados no trabalho foram: Dexametasona (um glicocorticoide com ação anti-inflamatória); Carragenina (agente flogístico que induziu a inflamação e um polissacarídeo sulfatado extraído da alga Chondros crispus); Cetamina; Xilazina.

RC: 85294

Disponível em: https://www.nucleodoconhecimento.com.br/quimica/anti-inflamatoria 


\subsubsection{COLETA E PROCESSAMENTO DAS AMOSTRAS}

A Kalanchoe pinnata foi coletada na Universidade Federal do Oeste do Pará, campus de Oriximiná - Pará, no período de setembro a outubro em que há maior incidência de radiação solar, devido ao verão amazônico, o que pode potencializar o teor de substâncias presentes na planta (MUZITANO et al., 2011). Para preparo do extrato, coletaram-se folhas de $K$. pinnata que foram submetidas à secagem em estufa com ventilação, a uma temperatura de $40^{\circ} \mathrm{C}$ até completa secagem. Após secagem, o material foi rasurado para realização posterior de extração dos constituintes.

\subsubsection{OBTENÇÕES DOS EXTRATOS}

Os extratos aquosos foram preparados de acordo com a metodologia de Decocção. O extrato bruto por decocção foi elaborado utilizando dois frascos ambares de vidro de capacidade para $1000 \mathrm{~mL}$ e manta aquecedora para preparo do banho-maria. A mistura obtida, após a decocção do material, foi mantida em repouso ao abrigo da luz. Posteriormente, procedeu-se a filtragem dos extratos os quais foram utilizados em seguida para testes anti-inflamatórios.

Para a obtenção do extrato metanólico foram utilizados 1,05 kg do material vegetal seco, triturados e distribuídos uniformemente em frascos de Erlenmeyer de $1000 \mathrm{~mL}$ (375 g de material a cada frasco). Em seguida, adicionou-se $400 \mathrm{~mL}$ de metanol e o material vegetal foi incubado em modo estático sem presença de luz por 2 dias. Posteriormente, a amostra foi submetida à filtração simples, e após isso o filtrado foi concentrado em evaporador rotativo para a obtenção do extrato $\mathrm{MeOH}-1(5,4 \mathrm{~g})$.

RC: 85294

Disponível em: https://www.nucleodoconhecimento.com.br/quimica/anti-inflamatoria 


\subsubsection{AVALIAÇÃO DA ATIVIDADE ANTI-INFLAMATÓRIA}

A atividade anti-inflamatória do extrato metanólico e extrato aquoso das folhas de $K$. pinnata foi avaliada pelo modelo inflamatório de bolsa de ar em ratos. Os fármacos utilizados foram: Dexametasona - um glicocorticoide com ação anti-inflamatória, a Carragenina (agente flogístico que induziu a inflamação) um polissacarídeo sulfatado extraído da alga Chondros crispus (Sigma-Aldrich ${ }^{\circledR}$ ), e o extrato. Cada ensaio foi constituído por três grupos, todos com cinco indivíduos $(n=5)$ : Primeiro grupo (controle negativo): onde os animais receberam veículo solução salina $0,9 \%$ e aplicados na parte intraescapular de cada animal + carragenina 1\%; Segundo grupo (controle positivo): onde os animais receberam dexametasona $600 \mu \mathrm{g} / \mathrm{kg}$ - i.p. + carragenina $1 \%$ na bolsa de ar; Terceiro grupo (grupo tratado): animais que receberam o extrato metanólico nas diferentes concentrações de $200 \mathrm{mg} / \mathrm{kg}$ e 400 $\mathrm{mg} / \mathrm{kg}$ e extrato aquoso nas diferentes diluições (Kp 0,1, 1 ou 10 \%) i.p.

Após indução do processo inflamatório e tratamentos, os animais foram sacrificados por deslocamento cervical. Antes da indução do processo inflamatório, os animais foram anestesiados por via intraperitoneal (IP) com cetamina $(80 \mathrm{mg} / \mathrm{kg})$ e xilazina $(15 \mathrm{mg} / \mathrm{kg})$.

\subsubsection{MODELOS DA BOLSA DE AR EM RATOS}

O experimento da bolsa foi realizado em um período de 10 dias. No primeiro dia foi feito a tricotomia e a "confecção" da bolsa de ar. A bolsa de ar foi feita, a partir da injeção subcutânea de $20 \mathrm{~mL}$ de ar estéril na região intraescapular dos ratos (EDWARD et al., 1981; TAO et al., 1999). No terceiro e no sexto dia após o início do experimento, as bolsas foram reinfladas com $10 \mathrm{~mL}$ de ar também estéril. No nono dia do experimento, foi injetado dentro da bolsa de ar $2 \mathrm{~mL}$ de carragenina $1 \%$ a qual corresponde o agente flogístico (induz inflamação), neste mesmo dia, uma hora antes da injeção da carragenina, é administrado por via intraperitoneal veículo ( $\mathrm{NaCl}$

RC: 85294

Disponível em: https://www.nucleodoconhecimento.com.br/quimica/anti-inflamatoria 
0,9\%), dexametasona, e Kalanchoe pinnata nas diferentes diluições, nos respectivos grupos. No décimo dia, dezesseis horas depois da administração de carragenina na bolsa de ar, os animais foram sacrificados por deslocamento cervical e então foi feito uma fissura na região anterior da bolsa para a retirada do exsudato, antes da retirada do exsudato, é injetado dentro da bolsa de ar $1 \mathrm{~mL}$ de solução salina com EDTA $0,1 \%$. O exsudato celular foi separado por centrifugação e armazenado em refrigeração de $-80^{\circ} \mathrm{C}$ para posterior dosagens de nitrito. A avaliação da efetividade da técnica é determinada pelo volume de exsudato formado e pelo número de células recrutadas. Logo após a abertura das bolsas, foi realizado a contagem total de leucócitos segundo Ribeiro et al. (2000).

\subsubsection{MENSURAÇÃO DO VOLUME DO EXSUDATO FORMADO}

O exsudato formado foi coletado da bolsa ar com uma pipeta Pasteur esterilizada, imediatamente após abertura da bolsa. O volume final foi mensurado pela diferença do volume total coletado menos $1 \mathrm{~mL}$ de solução salina com EDTA $0,1 \%$ adicionado na bolsa.

\subsubsection{CONTAGEM DE CÉLULAS}

Após a coleta de exsudato uma alíquota de $20 \mu \mathrm{l}$ foi retirada e adicionada a $180 \mu \mathrm{l}$ de solução salina com EDTA 0,1\%, posteriormente foi retirado desta mistura $20 \mu \mathrm{le}$ adicionado a $180 \mu \mathrm{l}$ do corante de Turk, a partir de então foi retirado uma alíquota da solução resultante para submissão a contagem do número total de células em câmara de Neubauer imediatamente após abertura das bolsas de ar.

\subsubsection{ENSAIO DE NITRITO}

O ensaio do nitrito será realizado pela adição de reagente de Griess no material a ser analisado. Este reagente é preparado pela mistura de volume de solução de

RC: 85294

Disponível em: https://www.nucleodoconhecimento.com.br/quimica/anti-inflamatoria 
naftil-etileno a 0,1\% com a solução de sulfanilamida a $1 \%$ em ácido fosfórico a $5 \%$. Um volume de $500 \mu \mathrm{L}$ de amostra é misturada com o mesmo volume de reagente de Griess. O resultado da reação é a coloração rosa púrpura do meio. Este será posteriormente medido em espectrofotômetro com comprimento de onda de $540 \mathrm{~nm}$. As concentrações de nitrito serão determinadas pela comparação com os resultados obtidos pela curva padrão de diluições seriadas de nitrito de sódio.

\subsubsection{MODELO DA GAIOLA METABÓLICA PARA AVALIAÇÃO DA TOXICOLOGIA}

Para avaliar as possíveis ações tóxicas de Kalanchoe pinnata testadas na administração i.p. em diferentes diluições nos animais, utiliza-se uma metodologia onde as substâncias-testes, em suas concentrações testadas são administradas via intraperitoneal a fim de avaliar a atividade hepática e renal dos animais. Para isso, os animais passaram por um período de adaptação de 3 dias nas gaiolas metabólicas, e ocorreu a administração das diluições de Kalanchoe pinnata, os animais foram colocados novamente nas gaiolas, para a coleta de urina acumulada de 24 horas. Após este período, os animais foram decapitados em guilhotina.

O sangue coletado foi centrifugado a $3.000 \mathrm{rpm}$ durante $15 \mathrm{~min}$. O plasma e a urina foram armazenados a $4 \stackrel{\circ}{ } \mathrm{C}$. Posteriormente, as amostras foram submetidas a dosagens bioquímicas, a partir da utilização de kits de ensaio bioquímico específicos, e analisados por espectrofotometria utilizando espectrofotômetro, aparelho que mede a quantidade de luz obtida, a partir das colorações das reações, em filtro de comprimento de onda específico para cada substância dosada, sendo a cor formada na reação, diretamente proporcional à atividade enzimática da substância analisada.

O material foi utilizado para dosagem dos seguintes parâmetros bioquímicos: proteínas totais e albumina, uréia e creatinina urinária e plasmática. Os animais

RC: 85294

Disponível em: https://www.nucleodoconhecimento.com.br/quimica/anti-inflamatoria 
foram divididos em grupos controle, onde receberam solução salina $0,9 \%$ e experimentais onde foi administrado Kalanchoe pinnata nas diferentes diluições testadas.

\subsubsection{DOSAGEM DE PROTEÍNAS TOTAIS E ALBUMINA}

A dosagem de proteínas totais do soro ou plasma e a fração de albumina foram avaliadas seguindo o princípio no qual a albumina tem a propriedade de se ligar a uma grande variedade de ânions orgânicos e moléculas complexas de corantes (LIMA, 1993; MOTTA, 2009). O sistema de medição se baseia no desvio do pico de absorvibilidade máxima de um corante complexo (verde de bromo cresol) quando se liga à albumina. A cor formada é medida colorimetricamente entre 600 e $640 \mathrm{~nm}$, sendo proporcional à quantidade de albumina na amostra até a concentração até 6,0 g/dl (LIMA, 1993; MOTTA, 2009). O kit Utilizado para esta dosagem foi produzido pelo laboratório LABTEST Diagnóstica, catálogo 19.

\subsubsection{DOSAGEM DE UREIA}

Na dosagem de uréia, o método utilizado foi baseado em Lima (1993) e Motta (2009) os quais consistem na observação de intensificação da coloração formada na reação da uréia, em meio alcalino, frente adição de salicilato e hipoclorito de sódio e sob a ação catalisadora do nitroprussiato de sódio. Foi utilizado o kit fabricado pelo laboratório LABTEST Diagnóstica, catálogo 27.

\subsubsection{DOSAGEM DE CREATININA}

O princípio para dosagem de creatinina tanto plasmática quanto urinária foi executado seguindo o princípio no qual a creatinina e outros componentes do soro tem como reação a solução de picrato em meio alcalino, tornando-se um complexo de cor vermelha que é medido fotometricamente. A adição de um acidulante abaixa

RC: 85294

Disponível em: https://www.nucleodoconhecimento.com.br/quimica/anti-inflamatoria 
o $\mathrm{pH}$ para 5.0, promovendo a composição do picrato de creatinina, possuindo uma permanência constante na cor decente desses cromogênios, que também será medida fotometricamente. A diferença entre essas duas leituras fornece o valor da creatinina verdadeira (LIMA, 1993; MOTTA, 2009).

O kit utilizado para esta dosagem foi produzido pela LABTEST Diagnóstica, catálogo 44. Essas análises dos níveis plasmáticos dos indicadores bioquímicos do metabolismo dos principais órgãos depuradores do sangue (fígado e rins) foram realizadas através de kits ELISA comerciais. E seguirão protocolos segundo Lima (1993) e Motta (2009).

\subsection{CARACTERIZAÇÃO QUÍMICA}

\subsubsection{EQUIPAMENTOS}

.Cromatógrafo Liquído de Alta Eficiência (HPLC);

.Evaporador rotativo - Modelo Quimis;

.Balança analítica Sartorius;

.Estufa - Modelo QUIMIS.

Cromatógrafo com Fase Gasosa (CG) acoplada a Espectrometria de Massas (CGEM) - Shimadzu Model: QP-2010.

\subsubsection{SOLVENTES}

Utilizados para caracterização química das amostras: metanol, hexano, dicloro metano (SYNTH e QUIMEX);

RC: 85294

Disponível em: https://www.nucleodoconhecimento.com.br/quimica/anti-inflamatoria 


\subsubsection{OBTENÇÕES DOS EXTRATOS}

\subsubsection{ABORDAGEM FITOQUÍMIA}

O extrato foi submetido a uma investigação dos constituintes químicos por classe metabólica, ou seja, triagem fitoquímica preliminar no qual é utilizada para se determinar quais metabólitos secundários estão presentes na droga vegetal. É bastante importante quando não se conhece o metabólito ativo da espécie em estudo. Os testes foram realizados seguindo-se a metodologia proposta por Costa (2001).

\subsubsection{SAPONINAS}

Uma solução mãe foi preparada com $420 \mathrm{mg}$ de cada extrato seco e $84 \mathrm{~mL}$ de água destilada separadamente. A solubilização do extrato ao solvente foi realizada em ultrassom. Após este procedimento, foi realizada uma filtração simples. A $2 \mathrm{~g}$ da droga vegetal, adicionou-se $10 \mathrm{~mL}$ de água deionizada, fervendo-se por 5 minutos. Filtrou-se a solução resultante para um tubo de ensaio, o qual foi agitado vigorosamente por 15 segundos. A ocorrência de espuma e sua permanência durante 15 minutos foi considerada como resultado positivo.

\subsubsection{FENÓIS E TANINOS}

Para verificação de presença de fenóis e taninos, primeiramente foram separados em tubos de ensaios $5 \mathrm{~mL}$ da solução de cada extrato (solução-mãe) obtido, em seguida foram adicionados $1 \mathrm{~mL}$ de solução alcoólica de $\mathrm{FeCl}_{3}$ a $1 \%$ em cada tubo, durante a mistura qualquer mudança na coloração ou formação de precipitado é indicativo de presença de fenóis e taninos. Todos os testes foram feitos em triplicata para cada extrato com intuito minimizar um possível erro.

RC: 85294

Disponível em: https://www.nucleodoconhecimento.com.br/quimica/anti-inflamatoria 


\subsubsection{FLAVONÓIDES}

Para verificar a presença de flavonoides, primeiramente foi preparada uma solução mãe cuja mistura consistia em $360 \mathrm{mg}$ dos extratos secos e $72 \mathrm{~mL}$ de metanol. Em seguida, o extrato foi filtrado e então se mediu $10 \mathrm{~mL}$ desta solução em cada 3 tubos de ensaios. Por conseguinte, adicionou-se $5 \mathrm{~mL}$ de $\mathrm{HCl}$ concentrado para cada tubo. Por fim, acrescentou-se a mistura raspas de magnésio, o surgimento de uma coloração rósea indicaria presença de flavonoides na solução.

\subsubsection{PURINAS}

Em uma cápsula de porcelana, juntou-se $5 \mathrm{mg}$ de extrato seco, 3 gotas de solução de $\mathrm{HCl}$ na concentração $6 \mathrm{~N}$ e 2 gotas de $\mathrm{H}_{2} \mathrm{O}_{2}$ concentrado. Evaporou-se em banho maria. Adicionou-se 3 gotas de solução de $\mathrm{NH}_{4} \mathrm{OH}$ na concentração $6 \mathrm{~N}$. $\mathrm{O}$ surgimento de coloração violeta indica reação positiva.

\subsubsection{GLICOSÍDEOS CARDIOTÔNICOS}

Para análise de glicosídeos cardiotônicos primeiramente se aqueceu, em banhomaria, $5 \mathrm{~g}$ do extrato vegetal misturado com $50 \mathrm{~mL}$ de etanol $70 \%$. A mistura resultante foi filtrada realizando-se em seguida, sobre o filtrado, a adição de $30 \mathrm{~mL}$ de água deionizada $+15 \mathrm{~mL}$ de solução de acetato de chumbo $10 \%$, após o surgimento de um precipitado a mistura foi novamente filtrada. Sobre o filtrado adicionou-se $10 \mathrm{~mL}$ de solução de fosfato ácido de sódio $10 \%$ e após agitação da mistura, o material foi novamente filtrado. O material resultante foi transferido para funil de separação e extraído com $15 \mathrm{~mL}$ de clorofórmio, tal processo foi repetido por duas vezes, juntando-se as fases orgânicas a qual foi evaporada até metade do volume. Sobre a solução resultante concentrada foram realizados as reações de Legal (onde a coloração vermelha indica resultado positivo), reação de Kedde (onde o resultado positivo é expresso por coloração vermelha a castanho fugaz), reação de

RC: 85294

Disponível em: https://www.nucleodoconhecimento.com.br/quimica/anti-inflamatoria 
Keller-Killiani (onde a formação de um anel castanho avermelhado é considerada resultado positivo), reação de Liebermann-Burchard (cujo resultado positivo é observado quando do surgimento de coloração castanha) e a reação de Pesez (novamente a coloração vermelha indica resultado positivo).

\subsubsection{PERFIL CROMATOGRÁFICO E CARACTERIZAÇÃO QUÍMICA}

O extrato metanólico e a acetato de etila das folhas de $K$. pinnata foram avaliados por Cromatografia Líquida de Alta Eficiência (CLAE) (Agilent@), 1200 series) com detector UV DAD. As análises foram realizadas em coluna de fase reversa C18 (25 $\mathrm{cm} \times 4,6 \mathrm{~cm} \times 5 \mu \mathrm{m}$ ); eluição em modo isocrático, fluxo de $0,6 \mathrm{~mL} / \mathrm{min}$, de fase móvel composta pela mistura de água:acetonitrila (8:2) concentração das amostras de 1 $\mathrm{mg} / \mathrm{mL}$, volume de injeção de $20 \mu \mathrm{L}$ e temperatura da coluna de $25^{\circ} \mathrm{C}$. A análise de cada amostra tiveram duração de 60 minutos, com pós time de 10 min entre as amostras. Os cromatogramas foram obtidos nos comprimentos de onda de 288 e $386 \mathrm{~nm}$ e nos espectros UV foram obtidos por varredura no UV (190 a $400 \mathrm{~nm}$ ).

Para obtenção do perfil cromatográfico e caracterização química do extrato metanólico e frações, foram utilizadas como marcadores químicos na CLAE as seguintes substâncias fenólicas padrão (Sigma-Aldrich®): canferol, luteolina, e apigenina 7-O- $\beta$-D- glicosídeo. Para estas análises dos padrões foi utilizado as mesmas condições cromatográficas, conseguindo obter os espectros por varredura no UV (190 a $400 \mathrm{~nm}$ ). Depois de obter os cromatogramas e espectros UV das amostras e marcadores químicos, após o reconhecimento de substâncias padrão nas amostras, teve como base desenvolver uma análise e comparação dos tempos de retenção dos ápices nos cromatogramas e dos espectros UV.

A fração hexânica, por conter substâncias apolares, foi submetida à análise por Cromatografia com Fase Gasosa (CG) acoplada a Espectrometria de Massas (CGEM). As análises foram realizadas no Núcleo de Pesquisa em Produtos Naturais e

RC: 85294

Disponível em: https://www.nucleodoconhecimento.com.br/quimica/anti-inflamatoria 
Sintéticos (USP - Ribeirão Preto, Brasil) utilizando cromatógrafo a gás (CG) equipado com uma coluna capilar de sílica fundida (HP-5, espessura do filme: $30 \mathrm{~m} x$ $0,25 \mathrm{~mm}, 0,25 \mu \mathrm{m}$ ), o período da corrida dura aproximadamente $60 \mathrm{~min}$, tendo o gás hélio como carreador com o fluxo de $10 \mathrm{~mL} / \mathrm{min}$; a temperatura inicial é de $300{ }^{\circ} \mathrm{C}$ chegando no máximo a $350{ }^{\circ} \mathrm{C}$. A detecção foi realizada através de espectrômetro de massa (EM), acoplado ao CG, com ionização eletrônica (IE) (70 eV e fonte de ion de $\left.250^{\circ} \mathrm{C}\right)$.

\subsection{TRATAMENTO ESTATÍSTICO (PESQUISA QUANTITATIVA)}

Estatística descritiva: Os resultados foram representados em colunas correspondentes à média mais ou menos desvio padrão da média ( \pm DPM) em gráficos de relação dose-efeito;

Estatística comparativa: Análise de variância de uma via ANOVA seguida de teste Bonferroni para múltiplas comparações para confirmação ou negação da hipótese das diferenças entre os grupos experimentais estabelecendo-se como limite de confidência $95 \%$ para a desigualdade.

\section{RESULTADOS E DISCURSÃO}

\subsection{AVALIAÇÃO DE ATIVIDADE ANTI-INFLAMATÓRIA DO EXTRATO AQUOSO}

\subsubsection{EFEITO DE KALANCHOE PINNATA SOBRE A MIGRAÇÃO DE CÉLULAS PARA O EXSUDATO INFLAMATÓRIO}

Figura 1- Efeito do extrato aquoso de Kalanchoe pinnata (i.p) administrado 1h antes da Carragenina (CG) $1 \%$ sobre os níveis de leucócitos no modelo de bolsa de ar

RC: 85294

Disponível em: https://www.nucleodoconhecimento.com.br/quimica/anti-inflamatoria 
induzida pela CG em ratos. Dados representados por média + EPM $(n=3) .{ }^{*} p<0,05$; ${ }^{* *} \mathrm{p}<0,01$

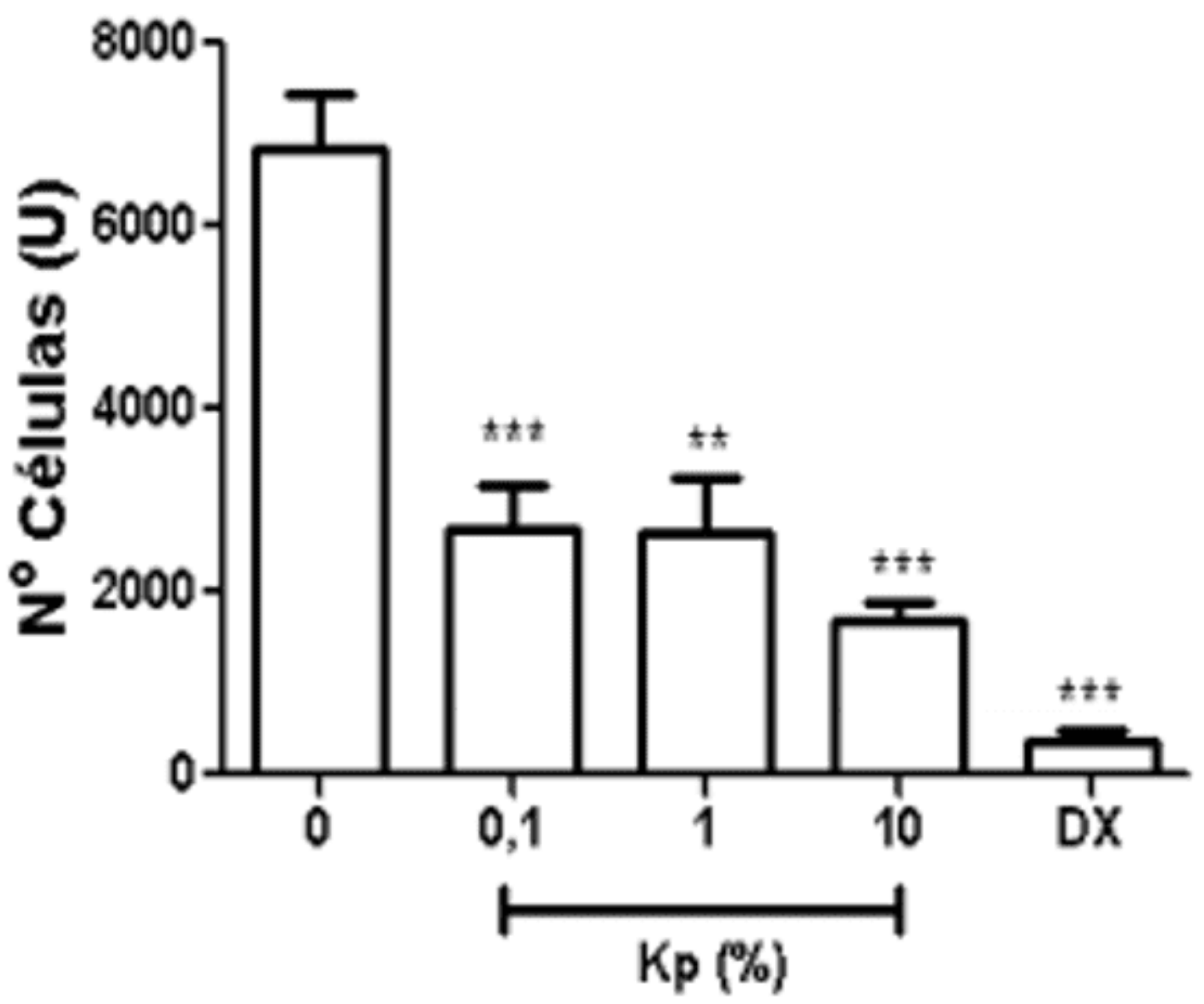

\section{Tratamento}

Fonte: Autor (2019)

$\mathrm{Na}$ figura 1 podemos observar uma diminuição no número de leucócitos infiltrados no exsudato em relação ao grupo controle, sendo que a diluição de $\mathrm{Kp}$ à $10 \%$, foi mais eficiente em provocar diminuição $75 \%$ comparado aos animais controles, e nas

RC: 85294

Disponível em: https://www.nucleodoconhecimento.com.br/quimica/anti-inflamatoria 
concentrações de $0,1 \%$ e $1 \%$, houve uma diminuição de aproximadamente $60 \%$. Com relação à potência dos efeitos anti-inflamatórios de Kp quando comparados à dexametasona, a inibição no volume de exsudato nas diluições de $0.1 \%$ e $1 \%$ foi de aproximadamente $65 \%$ para ambas do efeito da dexametasona, enquanto a dose de $\mathrm{Kp} 10 \%$ foi mais eficiente, alcançando valores próximos a $80 \%$. A administração dos extratos de $\mathrm{Kp}$ nas diluições $0,1,1$ e $10 \%$, resultaram em diminuição de uma faixa aproximada de 60 a $75 \%$ do número de células infiltradas no exsudato sem demonstrar um perfil dose-dependência.

No procedimento de inflamação, as células imunologicamente competentes são ativadas e agem em sentido de inutilizar ou eliminar esses microrganismos que são invasores, remove substâncias irritantes e proteínas antígenas, além de dar início a restauração tecidual, e consiste no recrutamento de leucócitos, extravasamento de várias proteínas plasmáticas e na ativação dos leucócitos e proteínas para eliminarem o estímulo inflamatório (Abbas \& Lichtman, 2005).

RC: 85294 


\subsubsection{EFEITO DE KALANCHOE PINNATA SOBRE O VOLUME DE EXSUDATO INFLAMATÓRIO}

Figura 2- Efeito do extrato aquoso de Kalanchoe pinnata (i.p) sobre os níveis de exsudação no modelo de bolsa de ar induzida pela CG em ratos. 0 - carragenina (1\%) somente. DX (dexametasona - $600 \mu \mathrm{g} / \mathrm{Kg}$, i.p. + CG (1\%). Dados representados por média + EPM $(n=3) .{ }^{*} p<0,05 ;{ }^{* *} p<0,01$.

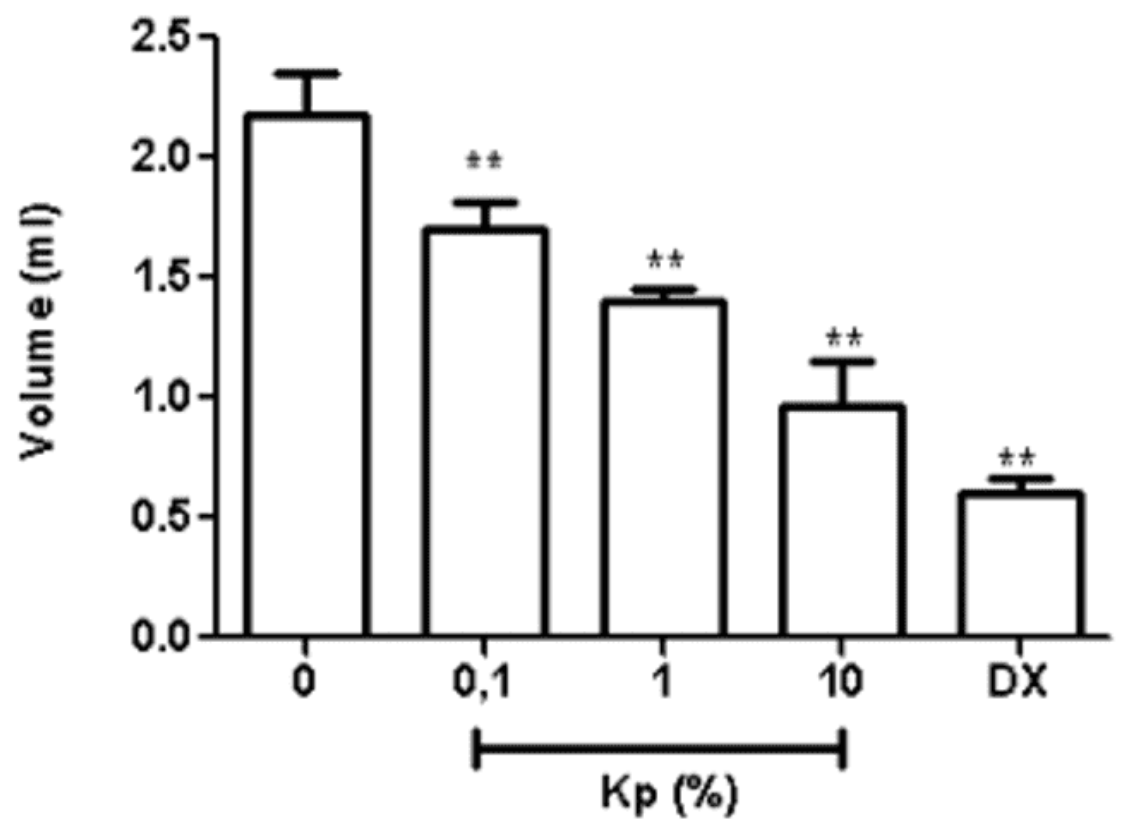

Tratamento

Fonte: Autor (2019).

Conforme Figura 2, ocorreu uma redução de 35\% (Kp à 1\%) e 55\% (Kp à10\%) do volume de exsudato, formado em resposta à administração de carragenina, em relação ao grupo controle. Quanto à potência dos efeitos anti-inflamatórios de $\mathrm{Kp}$ comparados à dexametasona, as diluições de $0,1 \%$ e $1 \%$ da inibição na produção do volume de exsudato foram de $66 \%$ do efeito da dexametasona, enquanto a diluição

RC: 85294

Disponível em: https://www.nucleodoconhecimento.com.br/quimica/anti-inflamatoria 
da dose de $\mathrm{Kp} 10 \%$ foi mais eficiente alcançando valores próximos a $80 \%$ e demonstrando um perfil dose-dependência.

Desta forma a formação do exsudato inflamatório está associada ao aumento da permeabilidade vascular, as primeiras aminas vasoativas liberadas na reação inflamatória agudas induzidas são histamina e serotonina, dando permissão saída de líquido rico em proteínas e de células para o tecido intersticial (KUMAR, et al 2008). As primeiras células que migram através do endotélio para o local infectado são neutrófilos (entre 4-12 h) e posteriormente monócitos (entre 24-48 h). Os monócitos, ao serem ativados tornam-se macrófagos, que além de exercerem sua ação como células fagocíticas, participam na ativação dos linfonodos e assim, na proliferação de linfócitos T (ABBAS; LICHTMAN; PILLAI, 2008).

Os resultados demonstram que, assim como a dexametasona, o extrato aquoso das folhas de $K$. pinnata reduziu o edema e migração de leucócitos, sendo eficaz na supressão do processo inflamatório induzido por carragenina.

RC: 85294 


\subsubsection{EFEITO DE KALANCHOE PINNATA SOBRE A PRODUÇÃO DE NITRITO NO EXSUDATO INFLAMATÓRIO}

Figura 3- Efeito de Kalanchoe pinnata sobre a produção de nitrito no exsudato inflamatório. Efeitos do extrato de Kalanchoe pinnata (i.p sobre a concentração de nitrito no exsudato em bolsas de ar de ratos tratados com carragenina 1\%). Dados representados por média + EPM $(n=3) .{ }^{*} p<0,05 ;{ }^{* *} p<0,01$.

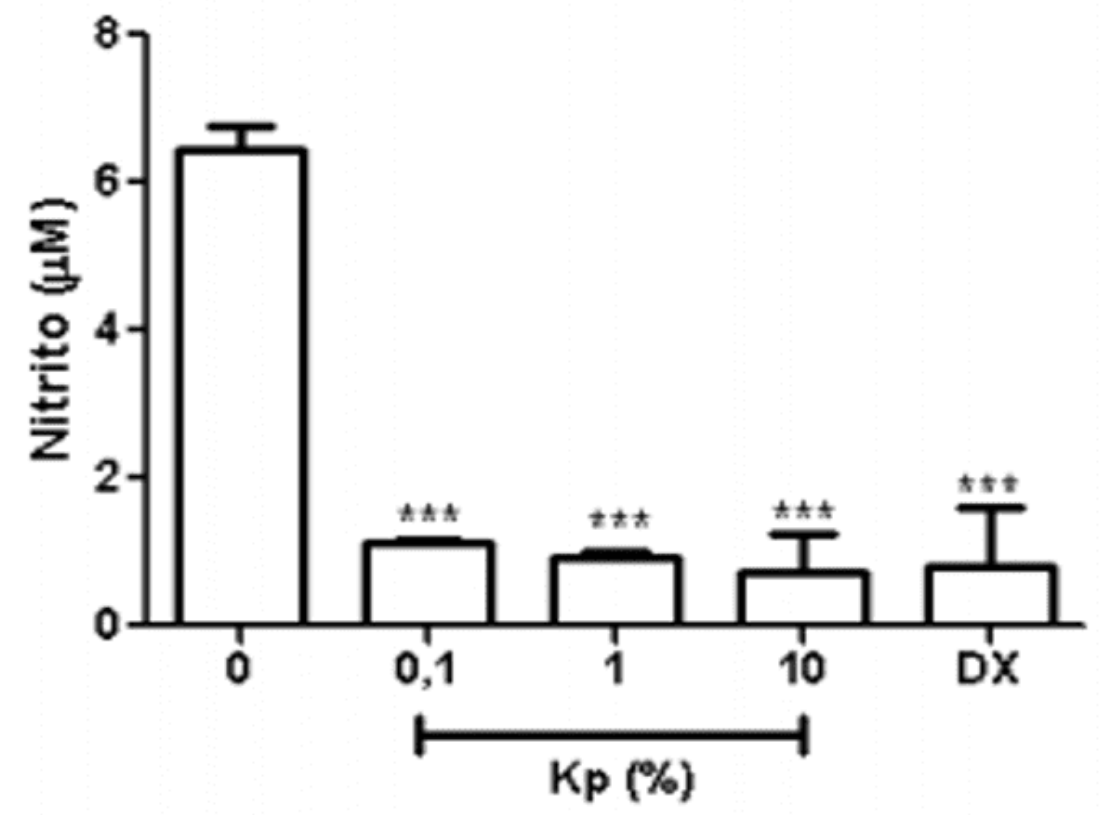

Tratamento

Fonte: Autor (2019)

A figura 3 mostra que ocorreu uma acentuada inibição com relação aos níveis de nitrito presentes no exsudato na ordem de $81 \%, 84 \%$ e $87 \%$, após os tratamentos de Kp $0,1 \%, 1 \%$ e $10 \%$, respectivamente. Tal inibição foi similar à provocada pela dexametasona, sugerindo que $\mathrm{Kp}$ pode atuar na diminuição a resposta inflamatória via mecanismo dependente da inibição da produção de óxido nítrico.

RC: 85294

Disponível em: https://www.nucleodoconhecimento.com.br/quimica/anti-inflamatoria 
Com relação aos níveis de nitrito presentes no exsudato, observou-se uma acentuada inibição. Tal inibição foi comparável à encontrada pela dexametasona, sugerindo que Kp pode atuar na diminuição de inflamação via mecanismo dependente da inibição da produção de óxido nítrico.

Conforme Mocada e colaboradores (1991) a ativação da enzima sintase de óxido nítrico induzida (NOSi) é resultado da produção de nitrito no exsudato, esse processo aumenta a produção de óxido nítrico (NO). Conforme a literatura diversos tipos celulares são capazes de sintetizar NO (WRIGT et al., 1989; DI ROSA et al., 2007), e esta substância tem um importante papel como neurotransmissor.

No caso da inflamação aguda gerada no modelo, podemos dizer que a administração extrato aquoso de Kp confirmou relatos de outros estudos para efeitos anti-inflamatórios, e apontou que um mecanismo associado à inibição da produção de NO via nitrito (medida indireta), visto que na figura 5 , houve uma diminuição de nitrito em todas as diluições testadas. O oxido nítrico modula reações inflamatórias agudas e crônicas e outros processos do sistema imunológico.

O papel do óxido nítrico na inflamação é um dos aspectos mais estudados na fisiologia nos últimos anos. Muitos estudos mostram um importante papel no NO como agente anti-inflamatório, porém muitos outros demonstram uma participação dessa molécula, tendo-a como indutora de ativação de células inflamatórias e dessas disfunções teciduais. Esse paradoxo aparentemente pode ser entendido estudando a química fisiológica do seu metabolismo e do NO determinado, possibilitando, uma distinção entre os efeitos deletérios e benéficos desse composto (GRISHAM et al., 1999).

A interação direta do NO representam as duas principais formas de efeitos biológicos deste composto nos sistemas como proteínas metálicas ou com radicais orgânicos livres (WINK et al., 1997; PADMAJA, HUIE, 1993). Em constante, os

RC: 85294

Disponível em: https://www.nucleodoconhecimento.com.br/quimica/anti-inflamatoria 
efeitos indiretos são mediados por espécies oxidas de nitrogênio altamente reativas, formadas pela reação do $\mathrm{NO}$ com $\mathrm{O}^{2} \mathrm{e} \mathrm{O}^{2-}$. Essas espécies estão associadas com a fisiopatologia de diversos modelos de inflamação (GRISHAM et al., 1998; NATHAN, 1997; WINK; MITCHELL, 1998) e as mais significantes são óxido nitroso $\left(\mathrm{N}_{2} \mathrm{O}_{3}\right)$ e peroxinitrito (ONOO-), que induzem dois tipos de estresse químico: oxidação e nitrosação (WINK; MITCHELL, 1998).

Como já foi relatado, pequenas moléculas têm efeitos fascinantes desde o começo da vida, por meio do controle da circulação placentária, além de efeitos letais consideráveis, tal como o choque séptico. Além disso, sua atividade na imunoregulação está presente na inflamação e nos mecanismos de autoimunidade (FILHO e ZILBERSTEIN, 2000).

Em virtude dos resultados positivos no modelo de bolsa de ar e da complexidade química dos derivados vegetais, não se pode afirmar que a ação anti-inflamatória de K. pinnata se dê por um único mecanismo de ação. A atividade anti-inflamatória de K. pinnata pode ser atribuída à presença de constituintes químicos, como o triterpeno a-amirina e os flavonoide canferol (COUTINHO; MUZITANO; COSTA, 2009; OTUKI et al., 2005).

RC: 85294

Disponível em: https://www.nucleodoconhecimento.com.br/quimica/anti-inflamatoria 


\subsubsection{EFEITOS DE EXTRATO AQUOSO DE KALANCHOE PINNATA (KP) SOBRE PARÂMETROS BIOQUÍMICOS PLASMÁTICOS}

Tabela 1- Efeito da Kalanchoe pinnata sobre os níveis plasmáticos de proteínas totais, albumina, ureia e creatinina. Dados apresentados por média \pm EPM ( $n=5-4)$. Valores de referência (1) Melo et al., (2012) - Centro de Bioterismo da FMUSP (2008), referência (2) Dantas et al (2006).

\section{Kalanchoe Pinnata}

\begin{tabular}{|c|c|c|c|c|c|}
\hline \multirow{2}{*}{$\begin{array}{l}\text { Parâmetros } \\
\text { Bioquímicos } \\
\text { plasmáticos }\end{array}$} & \multicolumn{4}{|c|}{ Grupos } & \multirow[b]{2}{*}{$\begin{array}{l}\text { Valores de } \\
\text { Referência }\end{array}$} \\
\hline & Controle & $\begin{array}{c}\text { K.p 0,1\% } \\
(0,01 \mathrm{mg} / \mathrm{kg})\end{array}$ & $\begin{array}{c}\text { K.p 1\% } \\
(0,1 \mathrm{mg} / \mathrm{kg})\end{array}$ & $\begin{array}{l}\text { K.p } 10 \% \\
(1 \mathrm{mg} / \mathrm{kg})\end{array}$ & \\
\hline $\begin{array}{l}\text { Proteinas } \\
\text { Totais (g/dl) }\end{array}$ & $7,4 \pm 0,16$ & $6,96 \pm 0,29$ & $7,3 \pm 0,7$ & $5,7 \pm 0,52$ & $5,2-10,4(\operatorname{ref} 1)$ \\
\hline Uréia (mg/dl) & $30 \pm 2,08$ & $50,33 \pm 5,66$ & $50,6 \pm 3,71$ & $37,6 \pm 3,84$ & $12,3-51,0(\operatorname{ref} 2)$ \\
\hline $\begin{array}{l}\text { Creatinina } \\
(\mathrm{mg} / \mathrm{dl})\end{array}$ & $0,4 \pm 0$ & $0,46 \pm 0,03$ & $0,43 \pm 0,03$ & $0,4 \pm 0$ & 0,4 a $0,64($ ref 1$)$ \\
\hline $\begin{array}{l}\text { Albumina } \\
\text { (mg/dl) }\end{array}$ & $3 \pm 0,1$ & $2,93 \pm 0,06$ & $3,03 \pm 0,23$ & $2,5 \pm 0,05$ & 2,8 a $6,1(\operatorname{ref} 1)$ \\
\hline
\end{tabular}

Fonte: Autor (2019).

Na tabela 1 não observamos diferenças nos níveis de proteínas totais presentes no plasma, pois o grupo controle apresentou níveis de 7,4 $\pm 0,16 \mathrm{~g} / \mathrm{dL}$, os grupos tratados com extrato aquoso de $\mathrm{Kp}$ nas diluições de $0,1 \%(0,01 \mathrm{mg} / \mathrm{kg}), 1 \%(0,1$ $\mathrm{mg} / \mathrm{kg}$ ) e $10 \%$ (1 mg/kg) apresentaram níveis de 7,3 $\pm 0,7 \mathrm{~g} / \mathrm{dL} ; 6,96 \pm 0,29 \mathrm{~g} / \mathrm{dL}$ e 5,7 $\pm 0,52$ respectivamente.

Quanto aos níveis de albumina plasmática no grupo controle quantificamos $3 \pm 0,1$ $\mathrm{mg} / \mathrm{dL}$ e nos grupos tratados 2,93 $\pm 0,06 \mathrm{mg} / \mathrm{dL}(0,1 \%), 3,03 \pm 0,23 \mathrm{mg} / \mathrm{dL}(1 \%)$ e 2,5 $\pm 0,05 \mathrm{mg} / \mathrm{dL}(10 \%)$. Por sua vez, a uréia é o principal produto formado no RC: 85294

Disponível em: https://www.nucleodoconhecimento.com.br/quimica/anti-inflamatoria 
catabolismo de proteínas e aminoácidos, embora, o grupo controle tenha apresentado níveis de uréia de $30 \pm 2,08 \mathrm{~g} / \mathrm{dL}$ e os grupos tratados apresentado

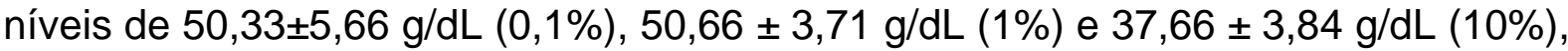
esses valores estão dentro da variação esperada, segundo outros autores. Os níveis de creatinina não mostraram diferenças significativas entre os grupos, sendo que o grupo controle apresentou níveis de 0,4 $\pm 0 \mathrm{mg} / \mathrm{dL}$ e os grupos tratados com $\mathrm{Kp} \mathrm{0,46}$ $\pm 0,03 \mathrm{mg} / \mathrm{dL}(0,1 \%), 0,43 \pm 0,03 \mathrm{mg} / \mathrm{dL}(1 \%)$ e $0,4 \pm 003 \mathrm{mg} / \mathrm{dL}$ (10\%). Caso houvesse uma elevação da creatinina plasmática seria traduzida como possível insuficiência renal aguda, que é referida na literatura como decorrente de diminuição do fluxo sanguíneo renal, que leva a uma disfunção renal.

\subsubsection{ATIVIDADE ANTI-INFLAMATÓRIA DO EXTRATO METANÓLICO DE KP}

A atividade anti-inflamatória de produtos naturais tem sido relacionada com a substâncias fenólicas, especialmente aos flavonoides, assim como aos agentes antioxidantes que, por meio de outros mecanismos, acabam por inibir os processos inflamatórios. Sob essa perspectiva, a hipótese da atividade anti-inflamatória do extrato metanólico, rico em substâncias flavonoídicas, em modelo de inflamação também foi testada.

A injeção de carragenina nos grupos de animais tratados induziu uma inflamação aguda, caracterizada pela formação de um exsudato e migração de leucócitos para a cavidade intraescapular. Desta forma, a coadministração a administração com extrato metanólico na dose de $400 \mathrm{mg} / \mathrm{Kg}$ dos extratos nas duas vias de administração via oral (v.o) e intraperitoneal (i.p.) reduziu significativamente o volume do exsudato inflamatório $(p<0,01)$ (figura 4) e a migração celular, porém não houve diferenças significativa na migração dos leucócitos comparado com o grupo padrão dexametasona $(p>0,05)$. Da mesma forma, os animais tratados com o anti-

RC: 85294

Disponível em: https://www.nucleodoconhecimento.com.br/quimica/anti-inflamatoria 
inflamatório dexametasona $\left(5 \mathrm{mg} / \mathrm{kg}^{-1}\right)$ reduziu o exsudato $(p<0,001)$ e também não modificou a migração celular comparados a dexametasona (Figura 5).

Figura 4-. Efeito da Kalanchoe pinnata sobre o acúmulo de exsudato induzido pela injeção de carragenina $(\mathrm{Cg})$ em ratos wistar, machos $(180-220 \mathrm{~g})$ em duas vias de administração. Cada ponto representa o volume médio de exsudato \pm EPM * $p<$ 0,001 e \# $p<0,01$, comparando com o grupo controle.

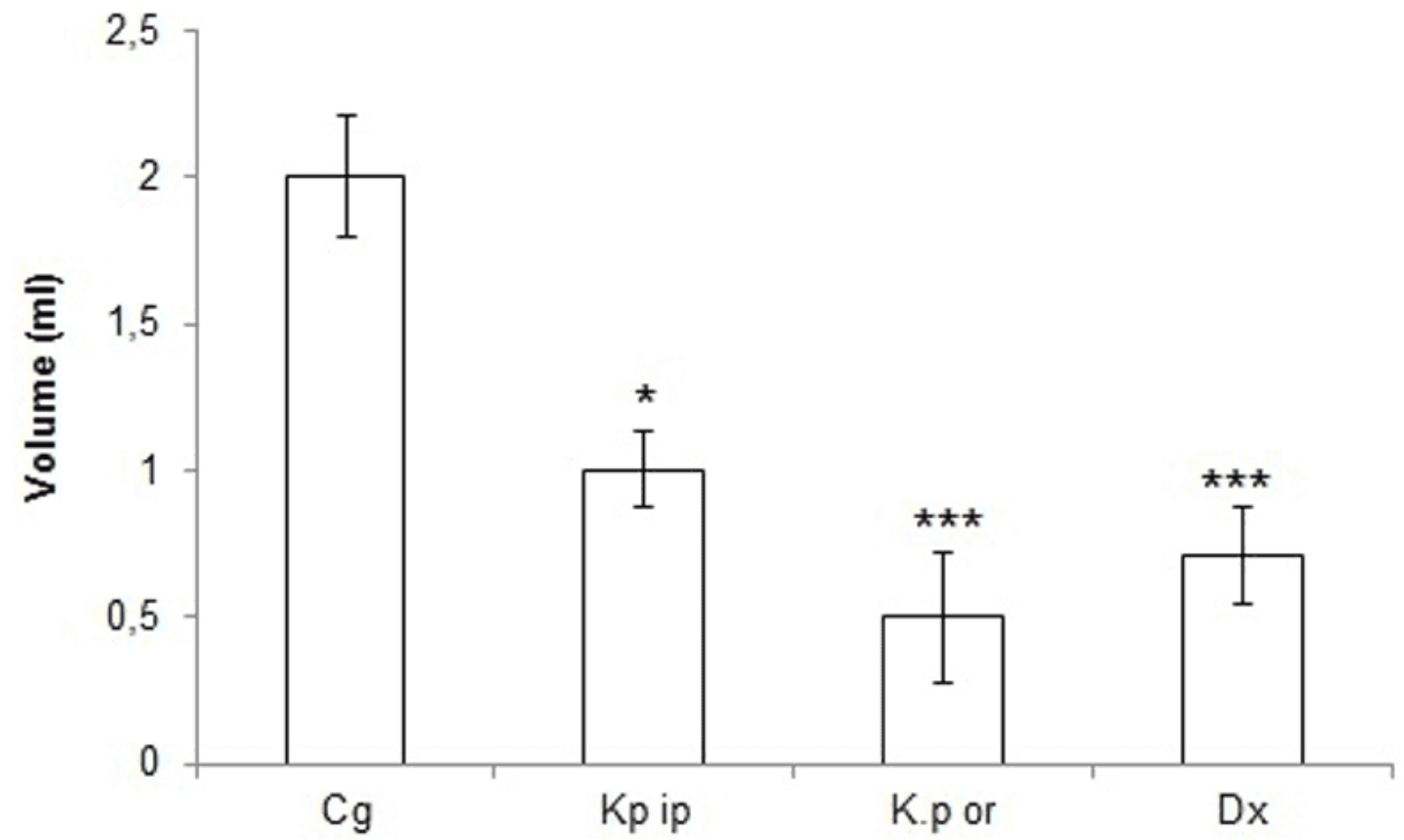

Fonte: Autor (2019)

RC: 85294

Disponível em: https://www.nucleodoconhecimento.com.br/quimica/anti-inflamatoria 
Figura 5- Contagem global de leucócitos no exsudato inflamatório de ratos, 16 horas após a injeção de carragenina. Houve diferenças significativas em comparação ao controle (Carragenina + solução salina), obtido por meio da ANOVA, teste de Tukey, p> 0,05.

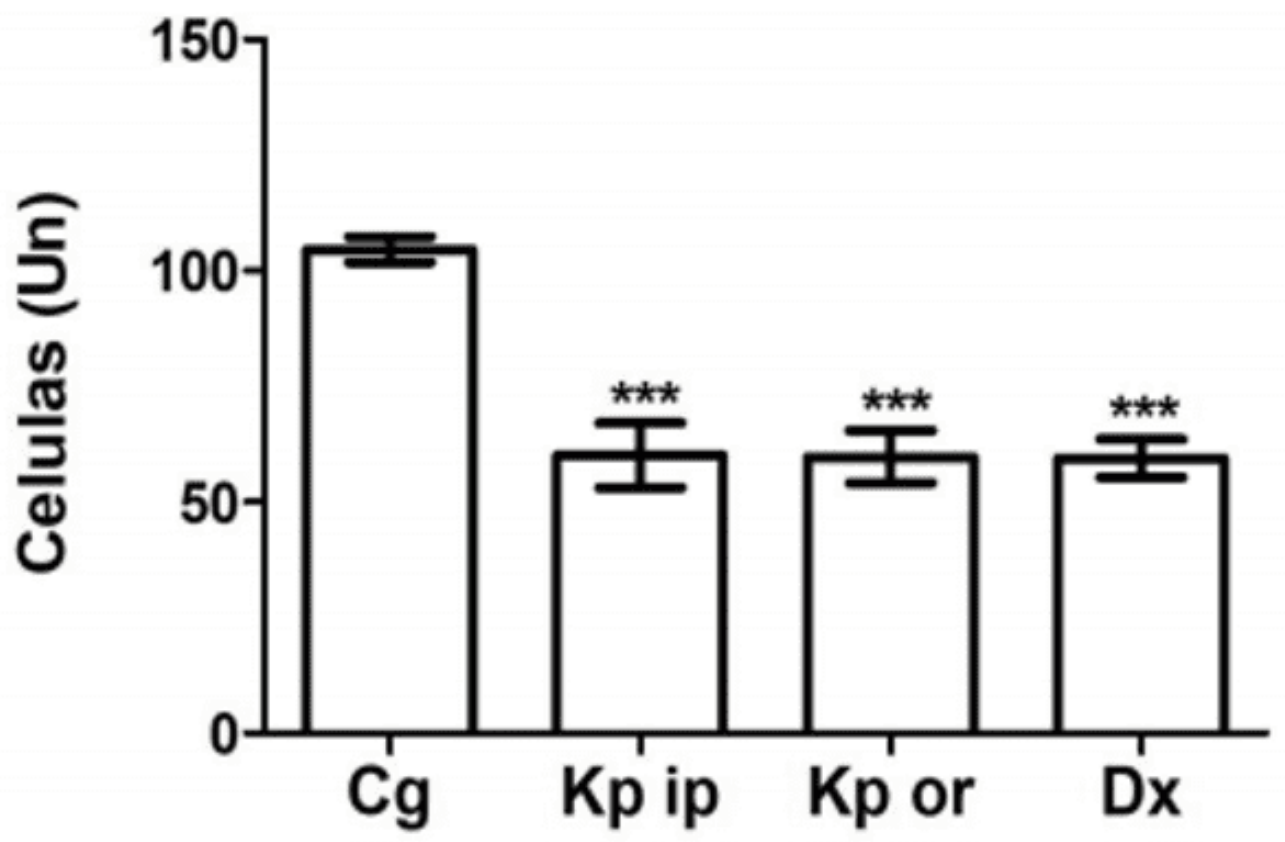

Fonte: Autor (2019).

Portanto, o efeito anti-inflamatório da espécie foi confirmado pelo modelo de bolsa de ar que demonstrou que as espécies Kalanchoe pinnata na dose $400 \mathrm{mg} / \mathrm{Kg}$ causaram a inibição da resposta inflamatória aguda verificada por meio da diminuição significativa do volume do exsudato comparada com o grupo controle além de demonstrou significativo efeito sobre a migração dos leucócitos na administração oral dos extratos. Verificou-se também que a atividade antiinflamatória da espécie estudada se assemelha com a dexametasona, visto que não existe uma diferença estatística entre elas $(p<0,05)$.

RC: 85294

Disponível em: https://www.nucleodoconhecimento.com.br/quimica/anti-inflamatoria 
O início da reação inflamatória envolve diferentes mecanismos. A resposta do desenvolvimento inflamatório induzido pela carragenina é definida na sua fase inicial por (0-1 hora) exercendo a liberação de histamina, serotonina e bradicinina. Com isso a fase posterior de (1-6 horas) com a elevação da produção de prostaglandinas está correlacionada, ativação da COX-2 e mais recentemente a liberação de NO (óxido nítrico), na resposta inflamatória. As drogas antiinflamatórias não esteroidais como a dexametasona age em receptores nucleares, estimula a expressão de proteínas anti-inflamatórias, como a lipocortina que inibe a PLA2 e, consequentemente, a produção de PGs. Além disso, inibe a síntese de COX, potencializando o efeito. Constituintes do extrato metanólico, principalmente os flavonoídicos, exercem mecanismo de ação parecido com a dexametasona (COUTINHO; MUZITANO; COSTA, 2009). (LIMA, 1999; CRUNKHORN; MEACOCK, 1971; NIEMEGEERS; VERBRUGGEN; JANSSEN, 1964).

\subsection{ANÁLISES FITOQUÍMICAS}

\subsubsection{TRIAGEM FITOQUÍMICA DAS PRINCIPAIS CLASSES DE METABÓLITOS SECUNDÁRIOSTRIAGEM FITOQUÍMICA DAS PRINCIPAIS CLASSES DE METABÓLITOS SECUNDÁRIOS}

A identificação de classes de metabólitos secundários e também de princípios ativos de determinada amostra vegetal podem ser obtidos pelo processo de prospecção fitoquímica. Geralmente várias substâncias são produzidas por uma planta dependendo de diversos fatores externos como clima, solo, hábitat, etc. Porém, em diversas plantas existem substâncias que são bastante comuns para certo vegetal, com isso podemos classificá-lo dependendo dos parâmetros e substancias encontrada na planta.

Os resultados de presença para fenóis, taninos, saponinas, flavonoides e glicosídeos realizados no trabalho com as folhas pulverizadas Kalanchoe pinnata RC: 85294

Disponível em: https://www.nucleodoconhecimento.com.br/quimica/anti-inflamatoria 
foram positivos. Tais resultados revelaram estes grupos químicos de substâncias como possíveis reveladores de matéria-prima para caracterização da Kalanchoe pinnata, tais resultado são observados na tabela 2 .

Tabela 2- Triagem fitoquímica das folhas de Kalanchoe pinnata.

\begin{tabular}{cc}
\hline Metabolitos Secundários & Kalanchoe pinnata \\
\hline Saponinas & Positivo $(+)$ \\
Fenóis e Taninos & Positivo $(+)$ \\
Flavonóides & Positivo $(+)$ \\
Purinas & Negativo $(-)$ \\
Glicosídeos cardiotônicos & Positivo $(+)$ \\
\hline
\end{tabular}

Fonte: Autor (2019).

A ocorrência de glicosídeos cardiotônicos já havia sido descrita por Smith (2004), bem como a ocorrência de flavonoides por Muzitano et al. (2006a) e Muzitano et al. (2011). As saponinas, presentes em K. pinnata, possuem caráter anfifílico e formam complexos com proteínas, conferindo a elas a capacidade de precipitar e coagular as células sanguíneas vermelhas, auxiliando a cessar o sangramento. Taninos condensados e taninos hidrolisáveis também podem formar complexos com proteínas, que podem potencializar a cura de feridas, queimaduras e mucosas inflamadas, formam uma proteção sobre o local e permitem que o processo de cura proceda naturalmente (OKWU; JOSIAH, 2006; SANTOS; MELLO, 2003; SCHENKEL et al., 2003; SIMÕES; SPITZER, 2003).

RC: 85294

Disponível em: https://www.nucleodoconhecimento.com.br/quimica/anti-inflamatoria 


\subsubsection{PERFIL CROMATOGRÁFICO E CARACTERIZAÇÃO QUÍMICA}

Conforme as figuras 6 a 9 os cromatogramas das frações obtidas a partir dos extratos brutos das folhas $K$. pinnata demonstraram que a fração metanólica e acetato de etila apresentaram a presença de dois picos majoritários, no tempo de retenção próximo de 20 minutos, e a partir desses aspectos visuais foi feito o fracionamento em coluna cromatográfica do extrato acetato de etila e extrato $\mathrm{MeOH}$ 1 além da utilização de padrões em CLAE para identificação de substâncias.

Para maior precisão da identificação de possíveis substâncias os extratos foram analisados e comparados em cumprimento de ondas de $288 \mathrm{~nm}$ e $386 \mathrm{~nm}$ (figura 6 A).

$\mathrm{Na}$ figura 6 são mostrados os cromatogramas da fração em acetato de etila das folhas de K. pinnata em $288 \mathrm{~nm}$ e $386 \mathrm{~nm}$. O pico 1 (Figura 6 A), com tempo de retenção (tr)16,09 min (em $386 \mathrm{~nm}$ ), produziu espectros de ultravioleta com bandas características do flavonoide canferol (Figura 7 B).

Após análise dos padrões para confirmação, nas mesmas condições, considerando o tempo de retenção e as características das bandas dos espectros de UV da substância padrão canferol (tr 15,54 min em 386 nm) (Figura 7 B) foi possível identificá-la na fração em acetato de etila.

RC: 85294

Disponível em: https://www.nucleodoconhecimento.com.br/quimica/anti-inflamatoria 
Figura 6- Perfis cromatográficos do extrato acetato das folhas de K. pinnata por CLAE UV obtidos em diferentes comprimentos de ondas.

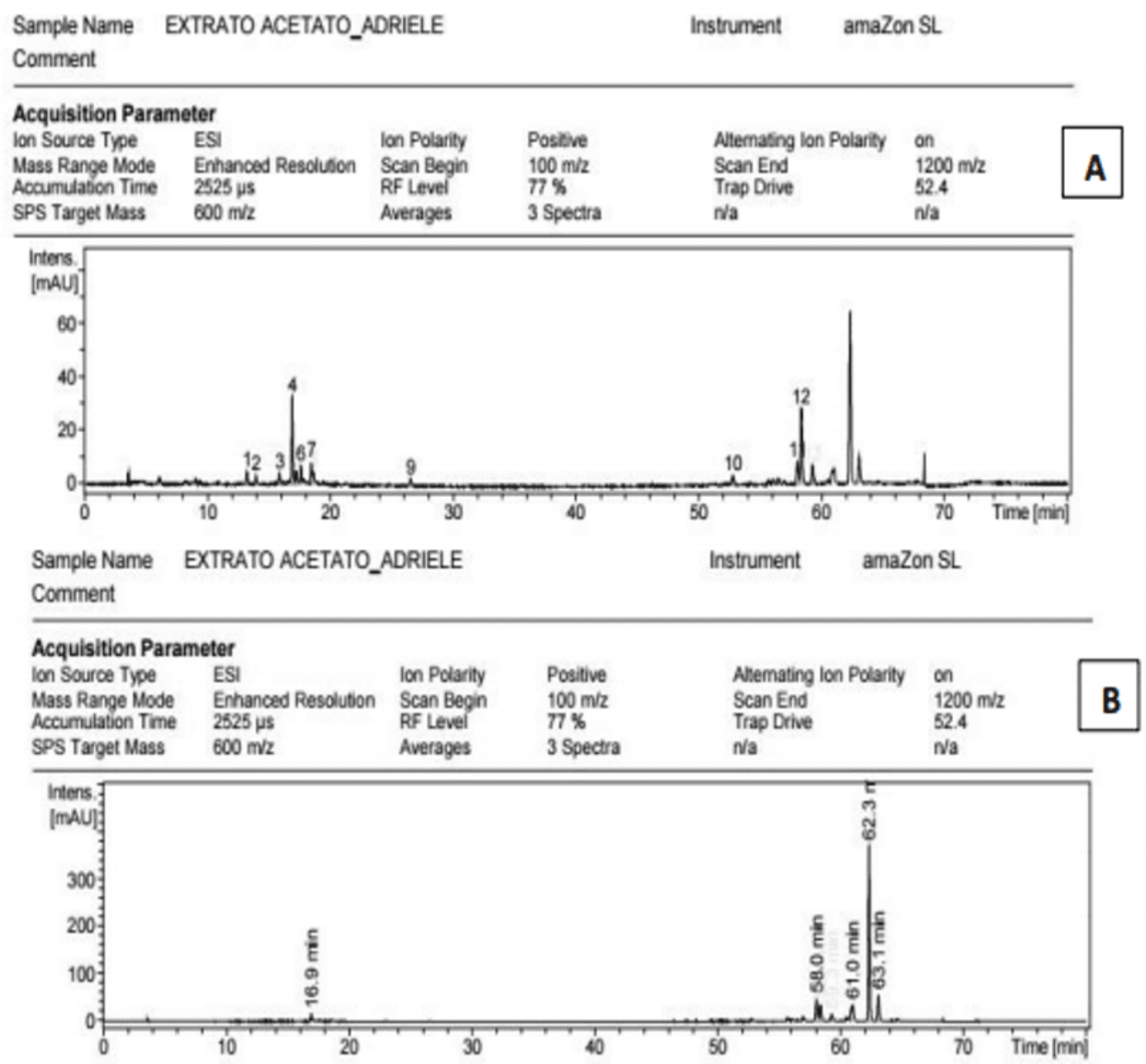

Cromatogramas obtidos em 288 (A) e $386 \mathrm{~nm}$ (B)

Fonte: O autor (2019).

RC: 85294

Disponível em: https://www.nucleodoconhecimento.com.br/quimica/anti-inflamatoria 
Figura 7- Espectros de UV do pico 1 e 2 do cromatograma do extrato acetato e do padrão químico Canferol.
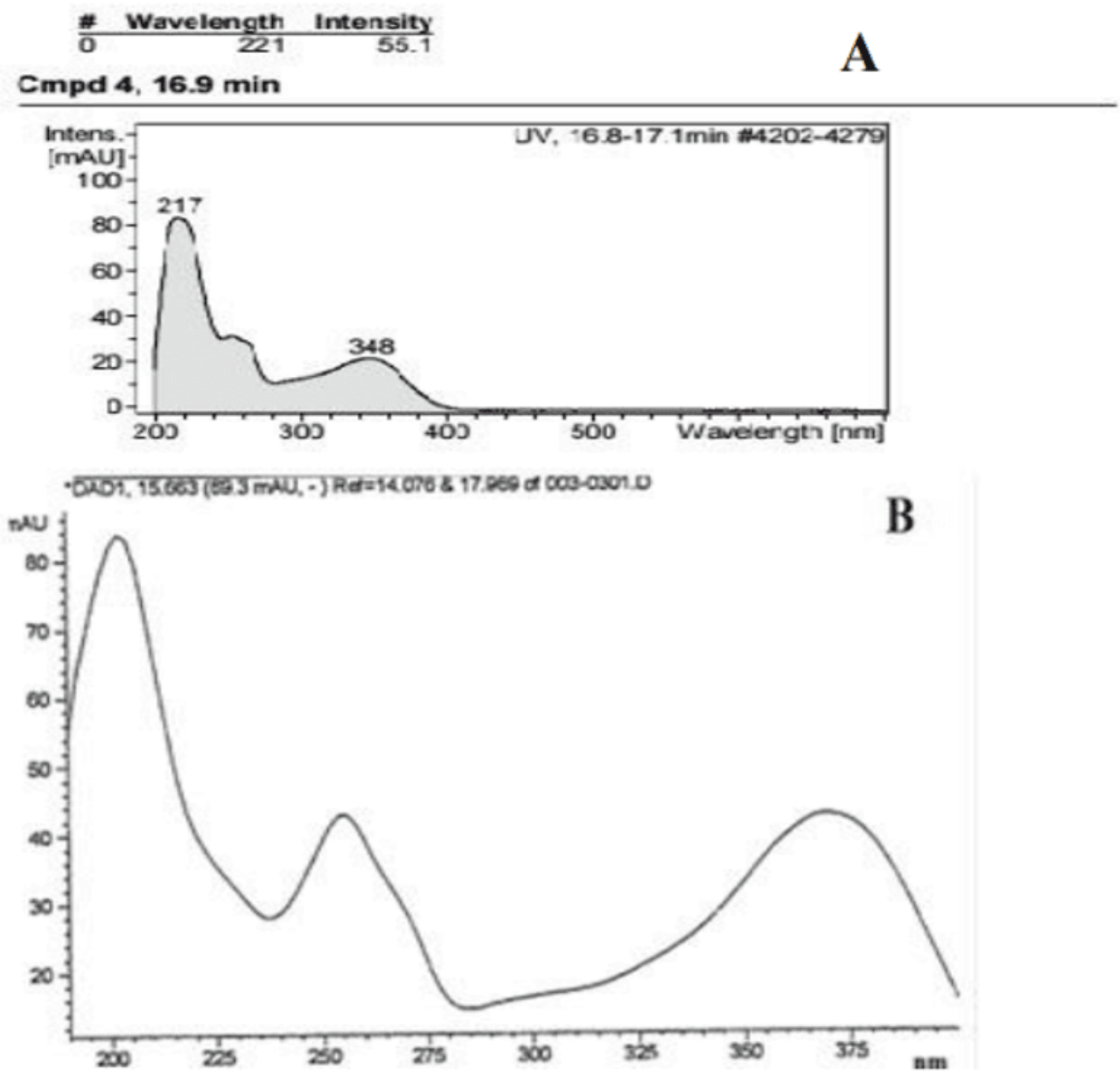

Pico l (A), Canferol (B)

Fonte: Autor (2019)

Cromatogramas da fração metanólica das folhas de K. pinnata obtidos em 288 (A) e 386 (B) nm são mostrados na Figura 8. O espectro de ultravioleta obtido a partir do pico 1, com tr 17,00 min (em $386 \mathrm{~nm}$ ), apresentou bandas correspondentes ao flavonoide canferol (Figura 9 B.)

RC: 85294

Disponível em: https://www.nucleodoconhecimento.com.br/quimica/anti-inflamatoria 
Para comprovar a presença dos flavonoides detectados com base no perfil cromatográfico, tempo de retenção e espectro de ultravioleta, padrões foram aplicados e analisados.

Após avaliação, o canferol apresentou perfil cromatográfico com tr 16,9 min (em 386 $\mathrm{nm}$ ), muito semelhante ao detectado na fração acetato de etila sendo o tempo de retenção para ambos bastante próximos. (Figura 6).

Conforme Coutinho e colaboradores (2009) a presença de flavonóis (canferol) podem exercer efeito anti-inflamatório por meio de inibição da PLA2, COX, LOX e iNOS, fortalece essa hipótesemecanística.

Figura 8- Perfis cromatográficos do extrato metanólico das folhas de K. pinnata por CLAE UV obtidos em diferentes comprimentos de ondas.
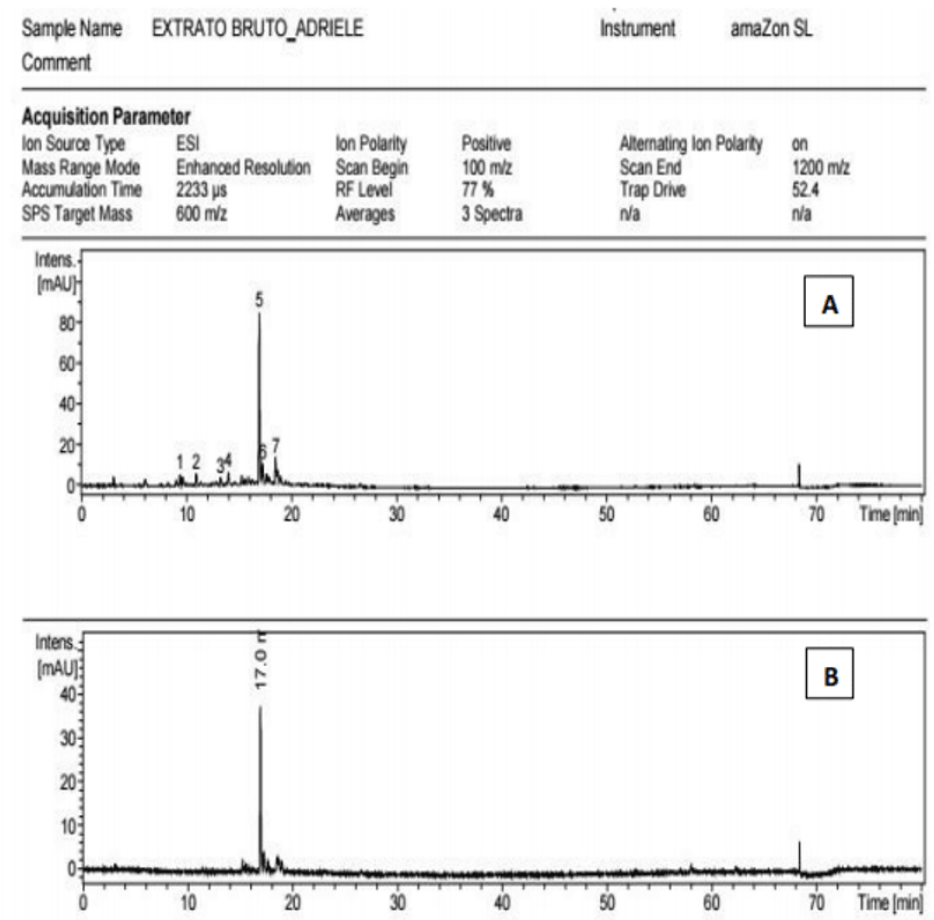

Cromatogramas obtidos em 288 (A) e $386 \mathrm{~nm}$ (B)

Fonte: O autor (2019).

RC: 85294

Disponível em: https://www.nucleodoconhecimento.com.br/quimica/anti-inflamatoria 
Figura 9- Espectros de UV do pico 1 e 2 do cromatograma do extrato metanólico e do padrão químico Canferol.
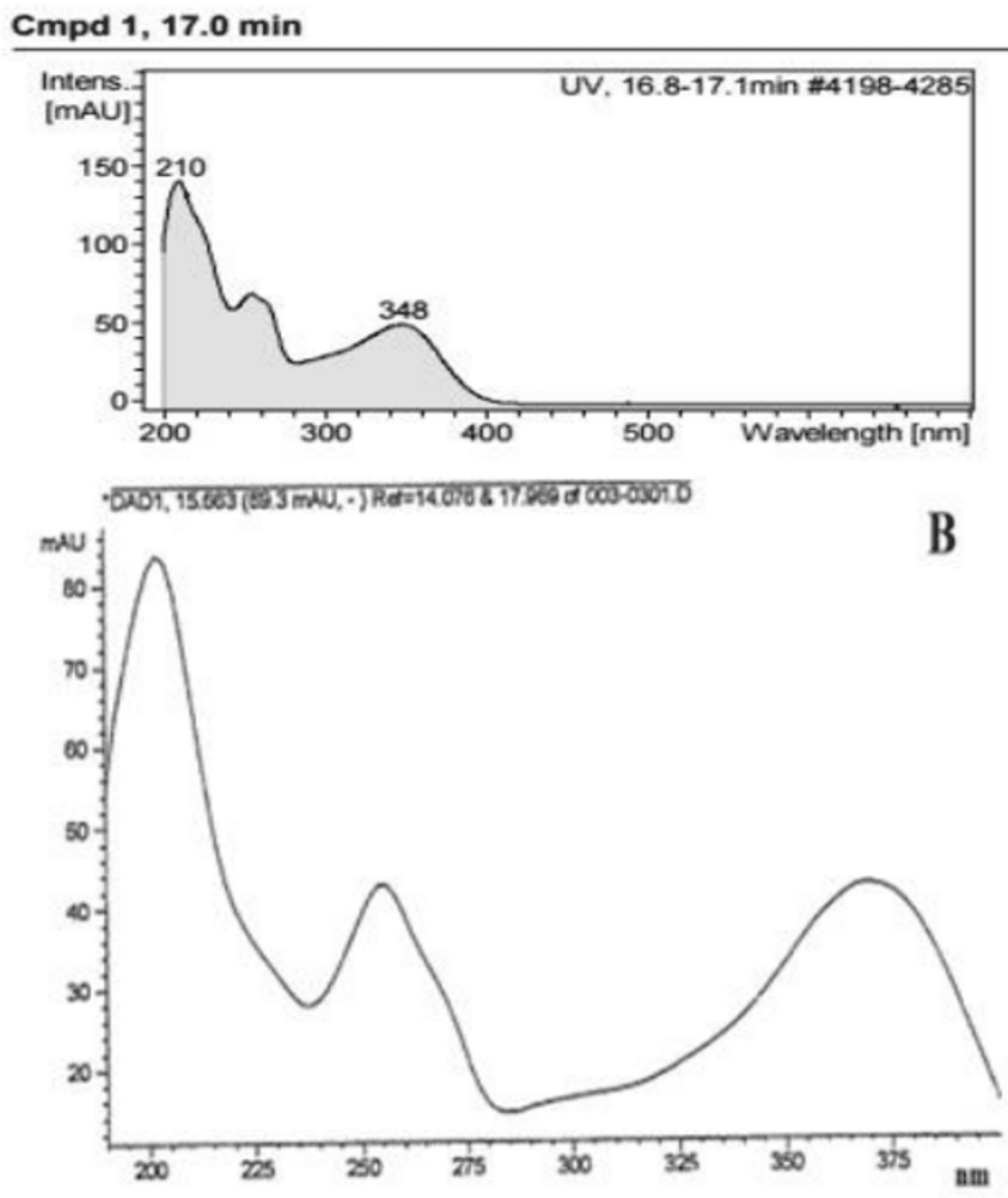

Pico 1 (A), Canferol (B)

Fonte: Autor (2019)

RC: 85294

Disponível em: https://www.nucleodoconhecimento.com.br/quimica/anti-inflamatoria 
Na Figura 10 é mostrado o perfil cromatográfico da fração hexânica das folhas de K. pinnata obtido por cromatografia com fase gasosa acoplada à espectrometria de massas (CGEM). Os picos majoritários foram observados nos tempos de retenção de 28,31 e 32 minutos.

Figura 10- Perfil cromatográfico da fração hexânica das folhas de K. pinnata obtido por CG-EM.

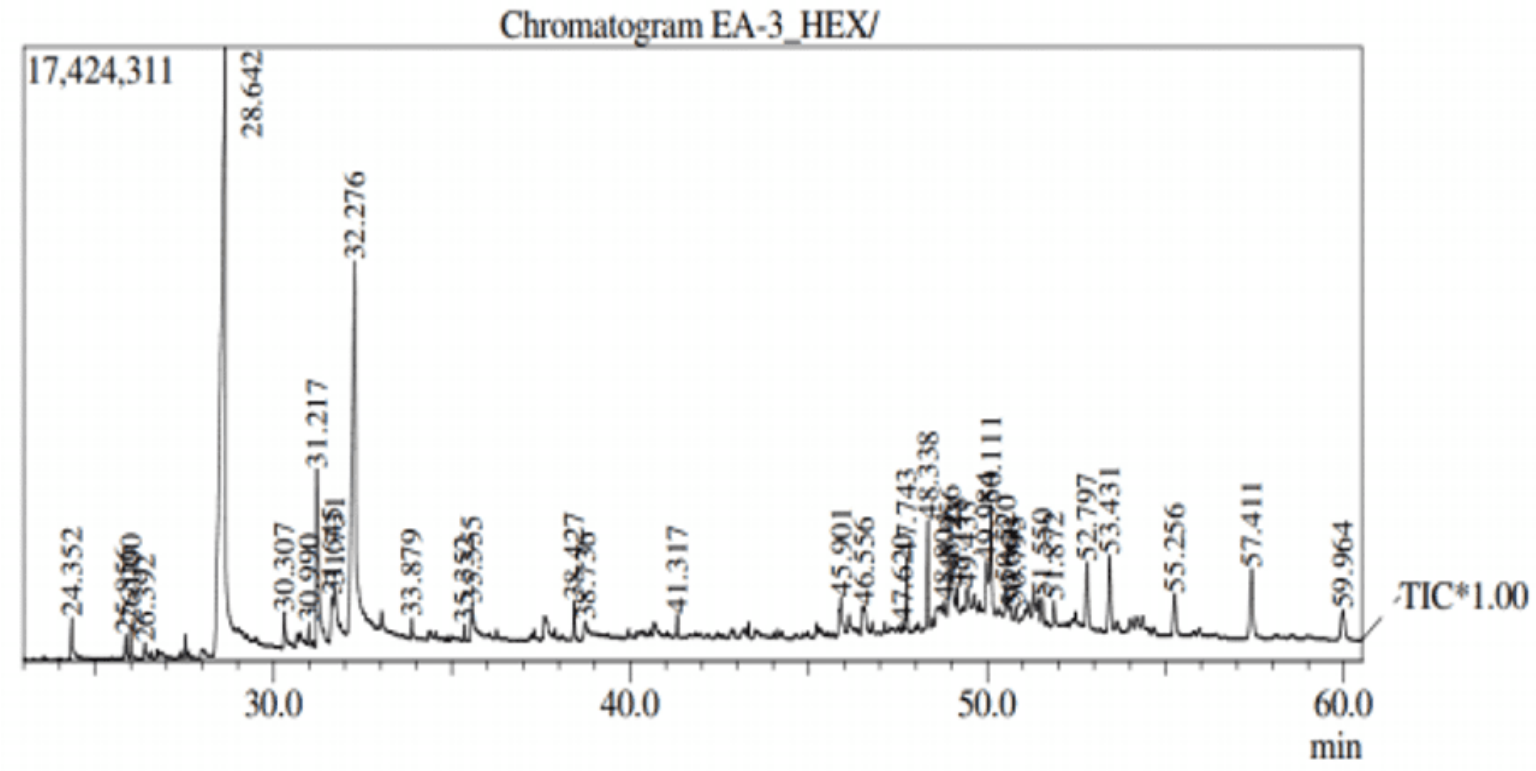

Fonte: Autor (2019)

Os constituintes químicos com maior abundância encontrados na fração hexânica foram o ácido hexadecanóico (palmitato de etila - 38,58\%), éster de etila do ácido 9 , 12 octadecadienóico (linoleato de etila - 1,50\%), éster de etila do ácido 9,12,15octadecanóico (ácido oleico - 17,70\%) e 3,7,11,15-tetrametil-2-hexadecen-1-ol (Phytol 5,71\%) (tabela 3). Os componentes identificados totalizaram 86,59\%, enquanto os nãos identificados foram $13,41 \%$. Os espectros de massas da $\alpha$-amirina e $\beta$-amirina (banco de dados) e do pico nos quais elas foram identificadas na fração hexânica estão representados na Figura 11 e 12 e as fórmulas estruturais da $\alpha$ amirina e $\beta$-amirina são apresentadas na Figura 13.

RC: 85294

Disponível em: https://www.nucleodoconhecimento.com.br/quimica/anti-inflamatoria 
Tabela 3- Constituintes químicos da fração hexânica obtidos das folhas de $K$. pinnata por CG-EM.

\begin{tabular}{|c|c|c|}
\hline Constituintes Químicos & $\begin{array}{l}\text { Tempo de retenção } \\
\text { (min) }\end{array}$ & $\begin{array}{l}\text { Concentração } \\
(\%)\end{array}$ \\
\hline Ácido hexadecanóico & 28,642 & 10,46 \\
\hline Ácido tetradecanóico & 24,352 & 0,95 \\
\hline Neofitadieno & 25,856 & 0,49 \\
\hline Ácido pentadecanóico & 26,392 & 0,29 \\
\hline 2-Metil-tricosane & 30,990 & 0,40 \\
\hline $\begin{array}{l}\text { Éster de etila do ácido 9, 12- } \\
\text { octadecadienóico }\end{array}$ & 31,645 & 1,5 \\
\hline Éster de etila do ácido octadecanóico & 32,276 & 12,70 \\
\hline Octadecanal & 47,743 & 1,53 \\
\hline Pentacosane & 48,338 & 2,22 \\
\hline Ácido Eicosanoico & 35,555 & 0,84 \\
\hline Vitamina $\mathrm{E}$ & 46,556 & 5,88 \\
\hline Tetracosano & 45,901 & 0,57 \\
\hline Ácido araquídico & 38,736 & 0,84 \\
\hline 8-Heptadeceno & 31,731 & 1,42 \\
\hline Éster de etila do ácido hexadecanóico & 49,148 & 1,06 \\
\hline 4,8,12,16-Tetrametilheptadecano & 35,352 & 0,24 \\
\hline Beta-amira & 49,433 & 5,87 \\
\hline Alfa- Amirina & 49,984 & 31,93 \\
\hline Octecanal & 50,111 & 2,84 \\
\hline Éster octadecil do ácido Hexadecanóico & 51,550 & 0,56 \\
\hline 3,7,11,15-tetrametil-2-hexadecen-1-ol & 31,217 & 5,71 \\
\hline Àcido triacontanóico & 48,804 & 0,35 \\
\hline
\end{tabular}

RC: 85294

Disponível em: https://www.nucleodoconhecimento.com.br/quimica/anti-inflamatoria 


\begin{tabular}{|l|l|l|}
\hline Sitosterol & 48,956 & 1,94 \\
\hline Ácido Acetiltributilcitrato & 33,879 & 0,32 \\
\hline Ácido Benzeno-1,3-dicarboxilico & 41,317 & 0,43 \\
\hline Ácido Benzeno-1,2-dicarboxilico & 38,427 & 0,72 \\
\hline Ácido icosanoico & 30,307 & 0,75 \\
\hline Phytone & 26,000 & 0,61 \\
\hline
\end{tabular}

Fonte: Autor (2017)

RC: 85294

Disponível em: https://www.nucleodoconhecimento.com.br/quimica/anti-inflamatoria 
Figura 11- Espectros de massas da $\beta$-amirina do banco de dados $(A)$ e do pico no qual ela foi identifica na amostra (B)

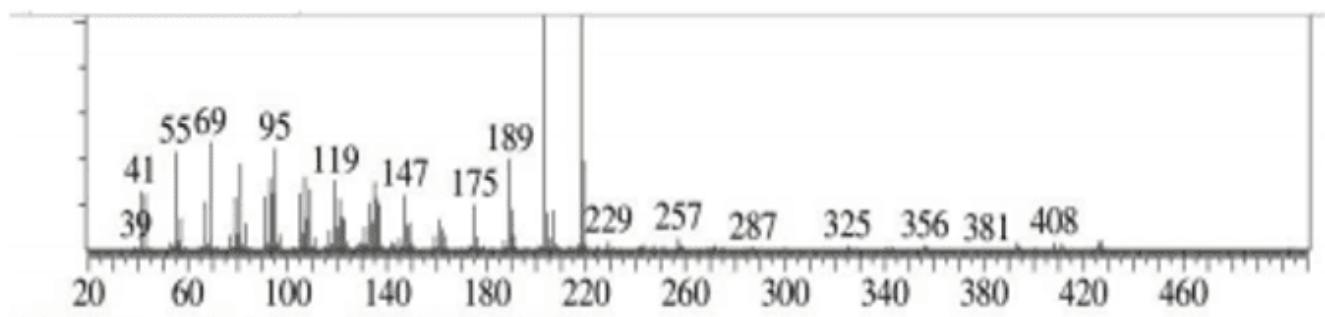

A

Hit\#:1 Entry:32 Library:MY LIBRARY.lib

SI:92 Formula:C30 H50 O CAS:559-70-6 MolWeight:426 RetIndex:0

CompName:Beta-amirina

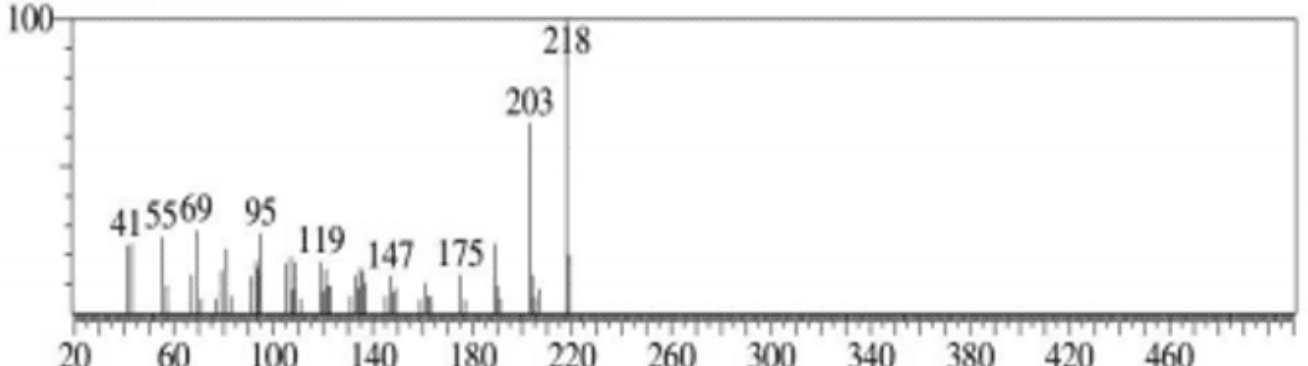

Hit\#:2 Entry:58 Library:MY LIBRARY.lib

SI:92 Formula:C30 H50 O CAS:559-70-6 MolWeight:426 RetIndex:0

CompName:Beta-amirina

im

Linet\#:26 R.Time:49.435(Scan\#:9088) MassPeaks:193

RawMode:Averaged 49.430-49.440(9087-9089) BasePeak:218.15(81834)

BG Mode:Calc. from Peak

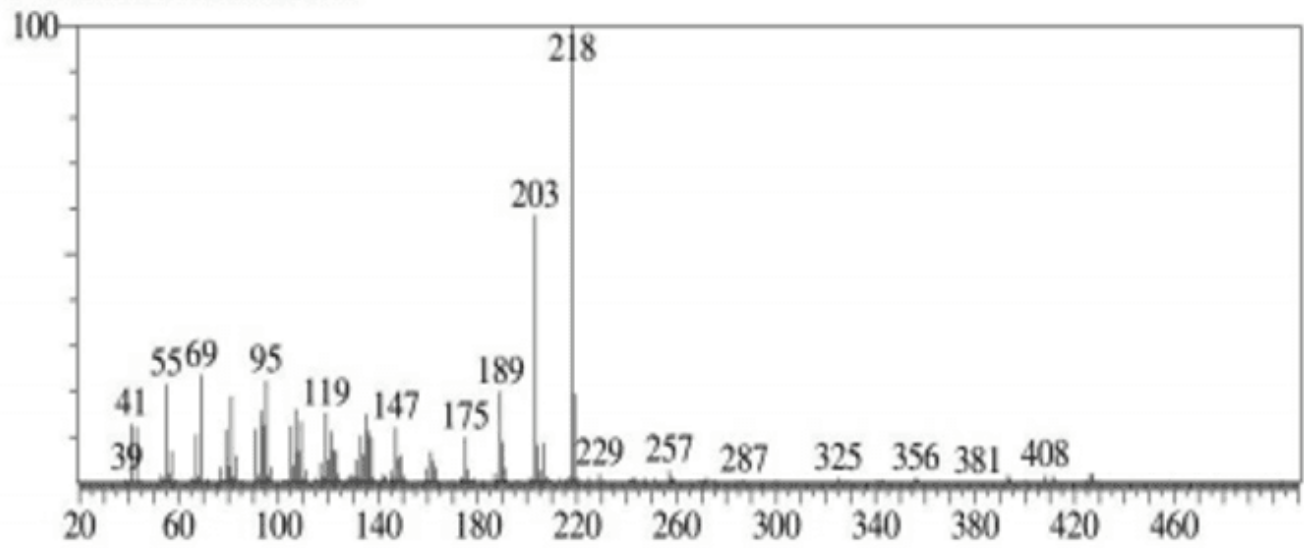

Fonte: Autor (2019)

RC: 85294

Disponível em: https://www.nucleodoconhecimento.com.br/quimica/anti-inflamatoria 
Figura 12- Espectros de massas da a-amirina do banco de dados (A) e do pico no qual ela foi identifica na amostra (B).

Hit\#:3 Entry:191128 Library:NIST11.lib

SI:91 Formula:C30H500 CAS:638-95-9 MolWeight:426 RetIndex:2873

CompName:.alpha.-Amyrin \$ Urs-12-en-3-ol, (3.beta.)- \$\$ Urs-12-en-3.beta.-ol \$\$ .alpha.-Amyran

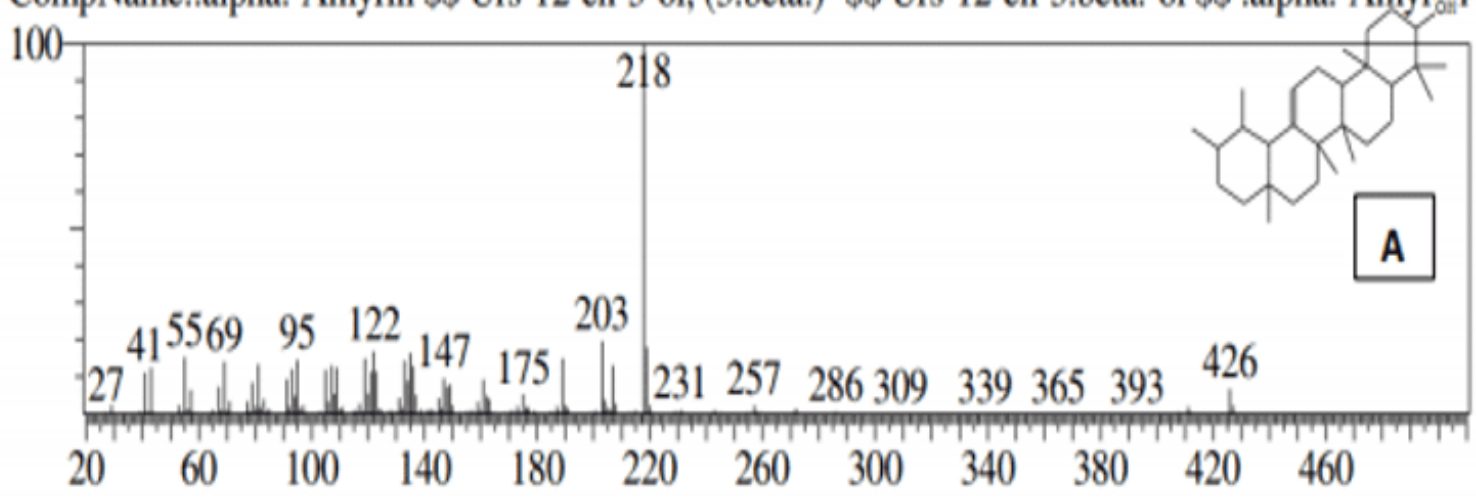

Line\#:27 R.Time:49.985(Scan\#:9198) MassPeaks:209

RawMode:Averaged 49.980-49.990(9197-9199) BasePeak:218.15(119312)

BG Mode:Calc. from Peak

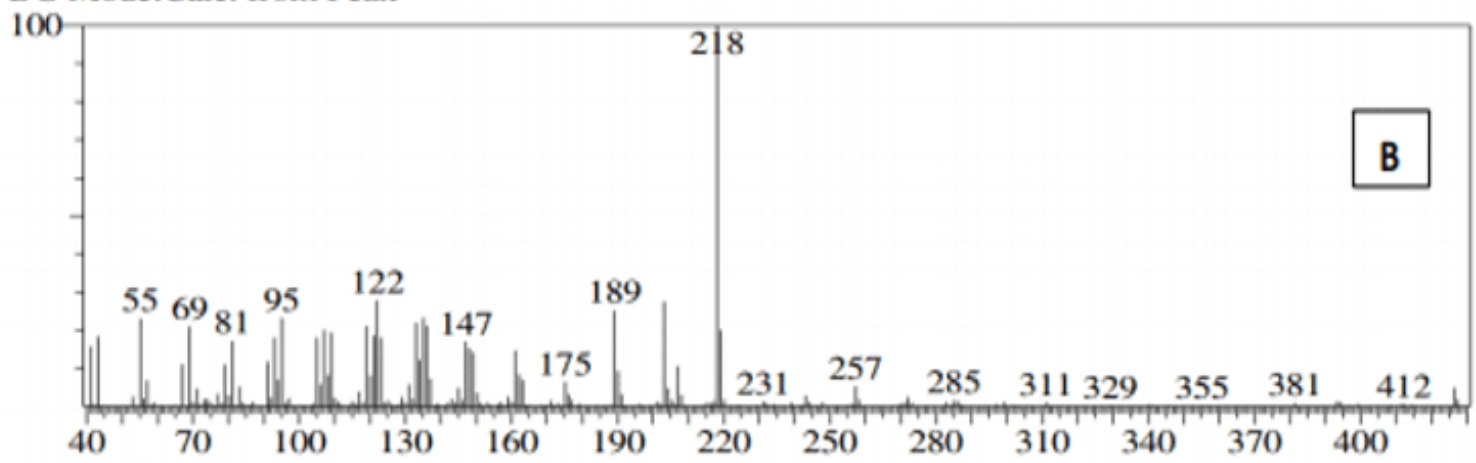

Hit\#:1 Entry:49 Library:MY LIBRARY.lib

SI:96 Formula:C30 H50 O CAS:638-95-9 MolWeight:426 RetIndex:0

CompName:Alfa-amirina

Fonte: O autor (2019)

RC: 85294

Disponível em: https://www.nucleodoconhecimento.com.br/quimica/anti-inflamatoria 
Figura 13- Fórmulas estruturais da $\alpha$-amirina e $\beta$-amirina.
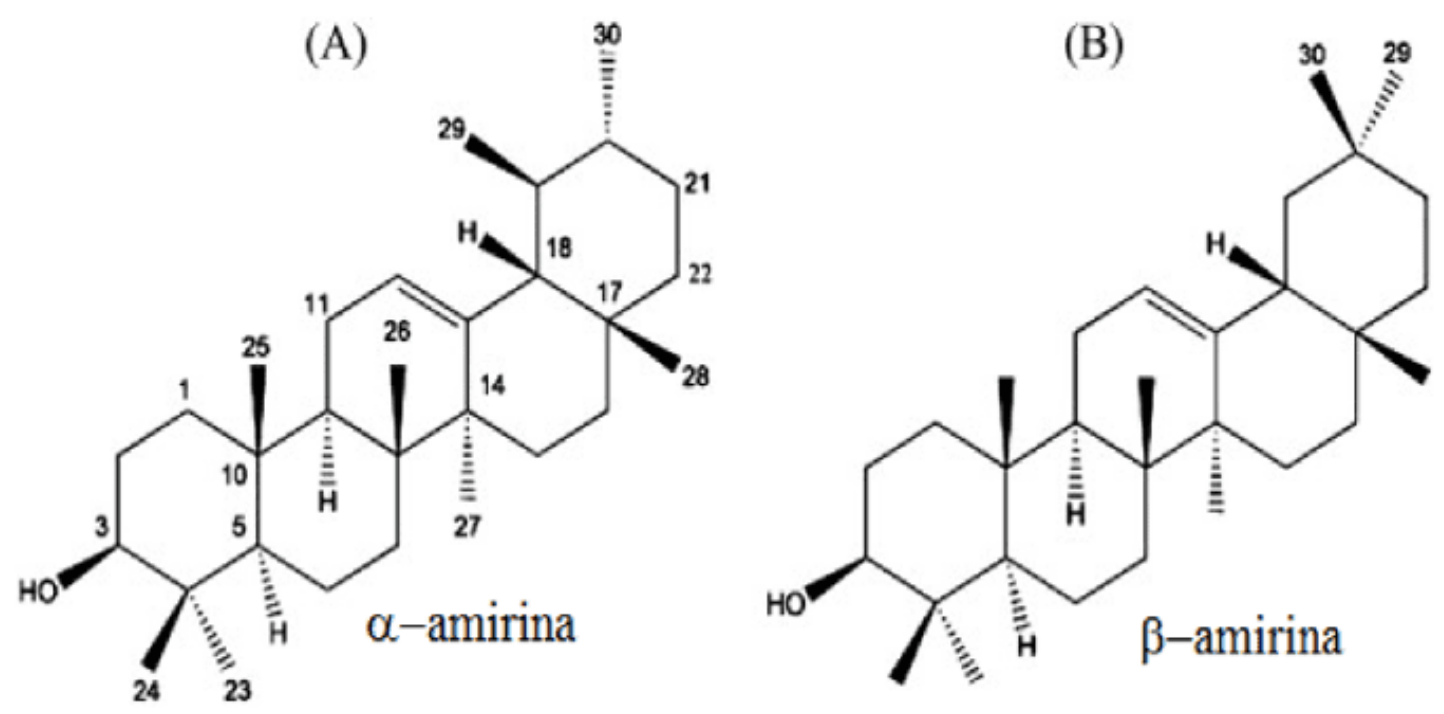

Fonte: Autor (2019).

Conforme a análise em CG-EM da fração hexânica, observa-se a identificação de alguns metabólitos tais como ésteres graxos e $\alpha$ - tocoferol (vitamina E), ambos citados na literatura como substâncias com potencial antioxidante. Ainda é também possível observar a presença do triterpeno pentacíclico a-amirina, esta substância, conforme a literatura, também apresenta potencial antioxidante e anti-inflamatório (DEWICK, 2009; DIAS; HAMERSKI; PINTO, 2011; DIAS; HAMERSKI; PINTO, 2011; FERNANDES, 2011; SILVA, 2007).

Conforme relatado por Otuki e colaboradores (2005), a a-amirina demonstrou atividade anti-inflamatória quando avaliada em modelos de inflamação, diminuindo a formação de edema, o influxo de neutrófilos e a expressão de IL-1 $\beta$. Ainda Medeiros et al. (2004) demonstraram que a diminuição dos níveis de prostaglandina E2 (PGE2), através do bloqueio da expressão da ciclooxigenase-2 (COX-2), via inibição das proteínas quinases e bloqueio da ativação do NF-kB, parecem representar os principais mecanismos envolvidos nas ações anti-inflamatórias tópicas da $\alpha$-amirina.

RC: 85294

Disponível em: https://www.nucleodoconhecimento.com.br/quimica/anti-inflamatoria 
Além do mais, Gokbulut et al. (2013), García-Mediavilla et al. (2007) e Majaz et al. (2011) relataram e justificaram a atividade antioxidante e anti-inflamatória em $K$. pinnata, associado ao efeito anti-inflamatório por inibição das vias do TNF- $\alpha-\mathrm{NO}$ e COX-II-PGE2.

Estudos comprovam que flavonoide identificado no extrato metanólico e acetato de K. pinnata, bem como a $\alpha$-amirina, possam contribuir para a ação anti-inflamatória pela inibição da via do AA (COUTINHO; MUZITANO; COSTA, 2009; GARCÍAMEDIAVILLA et al., 2007).

\section{CONCLUSÃO}

O ensaio experimental de indução de inflamação via carragenina em bolsa de ar indicou que tanto o extrato aquoso como o extrato metanólico bruto das folhas de Kalanchoe pinnata contém propriedades anti-inflamatórias, sendo que a administração por via oral do extrato metanólico foi mais eficiente para inibir ambos os parâmetros de volume de exsudato e migração leucocitária. A inibição nitrigérica sugere possível inibição da produção de óxido nítrico (NO). O flavonoide bioativo canferol foi identificado nos extratos metanólico e acetato por CLAE-UV e outra classe de â-amirina e a-amirina com picos identificados na fração hexânica por CGEM. Os resultados evidenciam que a espécie tem o potencial alvo para o desenvolvimento de formulações fitoterápicas, resultando assim novas possibilidades terapêuticas para a população.

\section{REFERÊNCIAS}

ABBAS, A.K.; LICHTMAN, A.H. Imunologia celular e molecular. 5th Edition, Elsevier, Rio de Janeiro, 2005.

ABBAS, A. K.; LICHTMAN, A. H.; PILLAI, S. Imunologia cellular e molecular. 6.ed. Elsevier, 2008, p. 576.

RC: 85294

Disponível em: https://www.nucleodoconhecimento.com.br/quimica/anti-inflamatoria 
AFZAL, M.; GUPTA, G.; KAZMI, I.; RAHMAN, M. AFZAL, O.; ALAM, J.; HAKEEM, K. R.; PRAVEZ, M.; GUPTA, R.; ANWAR, F.; Anti-inflammatory and analgesic potential of a novel steroidal derivative from Bryophyllum pinnatum. Fitoterapia, v.83, p.853858, 2012.

ALBUQUERQUE, U. P.; HANAZAKI, N. As pesquisas etnodirigidas na descoberta de novos fármacos de interesse médico e farmacêutico: fragilidades e perspectivas. Rev. Bras. Farmacogn -v.16 (Supl): 678-689. 2006.

ALMEIDA, A.P.; SILVA, S.A.G.; SOUZA, M.L.M.; LIMA, L.M.T.R.; ROSSIBERGMANN, B.; GONÇALVES DE MORAES, V.L.; COSTA, S.S. Isolation and chemical analysis of a fatty acid fraction of Kalanchoe pinnata with a potent Lymphocyte supressive activity. Planta Medica, v.66, p.134-137, 2000.

AKINPELU, D.A. Antimicrobial activity of Bryophyllum pinnatum leaves. Fitoterapia, v.71, p.193-194, 2000.

AKINSULIRE, O.R.; AIBINU, I. E.; ADANIPEKUN, T.; ADELOWOTAN,T.; ADUGBEMI, T. In vitro antimicrobial activity of crude extracts from plants Bryophyllum pinnatum and Kalanchoe crenata. African Journal of Traditional Complementary and Alternative Medicines, v.4, n. 3, p. 338-344. 2007.

BISWAS, S. K.; CHOWDHURY, A.; DAS, J.; KARMAKAR, U. K.; SHILL, M. C. Assessment of cytotoxicity and antibacterial activities of ethanolic extracts of Kalanchoe pinnata Linn. (Family: Crassulaceae) leaves and stems. International Journal of Pharmaceutical Sciences and Research, v. 2, n.10, p. 2605-2609, 2011.

BRASIL. Ministério da Saúde. Plantas medicinais de interesse ao SUS. Disponível em:Bryophyllum pinnatum. Pharmacologyonline v.2, p. 873-886, 2009.

RC: 85294

Disponível em: https://www.nucleodoconhecimento.com.br/quimica/anti-inflamatoria 
CENTRO DE BIOTERISMO DA FMUSP. Parâmetros bioquímicos de ratos do centro de bioterismo da FMUSP, 2008. Disponível em: http://www.biot.fm.usp.br/index.php?mpg=03.00.00\&tip=RATO\&id_ani=17\&parametr os=sim. Acessado em 10/05/2019.

CHOI, S. J.; TAI, B. H.; CUONG, N. M.; KIM, Y. H.; JANG, H. D. Antioxidative and anti-inflammatory effect of quercetina and its glycosides isolated from mampat (Cratoxylum formosum). Food Science Biotechnology, v. 21, n. 2, p. 587-595, 2012.

COUTINHO, M. A. S.; MUZITANO, M. F.; COSTA, S. S. Flavonoides: potenciais agentes terapêuticos para o processo inflamatório. Revista Virtual de Química, v. 1, n. 3, p. 241-256, 2009.

COSTA, A.F. Farmacognosia: farmacognosia experimental. 3. ed. Lisboa: Calouste Gulbenkian. v. 3, p. 303, 308-309; 2001.

COSTA, S.S; MUZITANO, M. F.; CAMARGO, L. M.; COUTINHO, A. S. M. Therapeutic Potential of Kalanchoe Species: Flavonoides and other Secondary Metabolites. Natural Product Communications, v. 3, n. 12, p. 2151-2164, 2008.

CRUNKHORN, P., MEACOCK S.C. Mediators of inflammations induced in the rat paw by carrageenan. British Journal of Pharmacology, v.1, n.42, p. 392-402, 1971.

CRUZ, E. A.; DA-SILVA, S. A. G.; MUZITANO, M. F.; SILVA, P. M. R.; COSTA, S.S.; ROSSI-BERGMANN, B. Immunomodulatory pretreatment with Kalanchoe pinnata extract 12and its quercitrin flavonoid effectively protects mice against fatal anaphylactic shock. International Immunopharmacology, v. 8, p. 1616-1621, 2008. 
CRUZ, B. P.; CHEDIER, L. M.; FABRI, R. L.; PIMENTA, D. S. Chemical and agronomic development of Kalanchoe brasiliensis Camb. and Kalanchoe pinnata (Lamk.) Pers under light and temperature levels. Anais da Academia Brasileira de Ciências, v. 83, n. 4, p. 1434-1441, 2011.

CRUZ, E.A.; REUTER, S.; MARTIN, H.; DEHZAD, N.; MUZITANO, M. F.; COSTA, S.S; ROSSI-BERGMANN, B.; BUHL, R.; STASSEN M.; TAUBE, C. Kalanchoe pinnata inhibits mast cells activation and prevents allergic airway. Phytomedicine, $v$. 19, p. 115-121, 2012.

DANTAS, J.A.; AMBIEL, C.R.; CUMAN, R.K.N.; BARONI, S.; BERSANI-AMADO, C.A. Valores de referência de alguns parâmetros fisiológicos de ratos do Biotério Central da Universidade Estadual de Maringá, Estado do Paraná. Acta Sci. Health Sci., 28(2):165-170 (2006).

DEWICK, P.M. Medicinal Natural Products: A Biosynthetic Approach. 3rd Edition, John Wiley \& Sons, New York. (2009).

DIAS, MARLUCE OLIVEIRA; HAMERSKI, LIDILHONE and PINTO, ANGELO C. Semi-preparative separation of $\alpha$ and $\beta$-amyrin by high performance liquid chromatographic. Quím. Nova [online]. 2011, vol.34, n.4, pp.704-706.

DI ROSA P., VILLAESCUSA J.C., LONGOBARDI E., IOTTI G., FERRETTI E., DIAZ V.M. Homeodomain transcription factor Prep1 (pKnox1) is required for hematopoietic stem cells and progenitors activity.Dev. Biol.. 311, 324-334. (2007).

EL ABDELLAOUI, S.; DESTANDAU, E.; TORIBIO, A.; ELFAKIR, C.; LAFOSSE, M.; RENIMEL, I.; ANDRÉ, P.; CANCELLIERI,P.; LANDEMARRE, L. Bioactive molecules in Kalanchoe pinnata leaves: extraction, purification, and identification. Analytical and Bioanalytical Chemistry, v. 398, p.1329-1338, 2010.

RC: 85294

Disponível em: https://www.nucleodoconhecimento.com.br/quimica/anti-inflamatoria 
FERNANDES, C. P. Estudo fitoquímico e biológico da espécie vegetal Manilkara subsericea (Mart.) Dubard. 2011. Dissertação de Mestrado Universidade Federal Fluminense, Niterói, RJ, 2011.

FETROW, C. W.; AVILA, J. R. Manual de medicina alternativa para o profissional. RJ: Guanabara Koogan, 2000. p. 158-60.

FILHO, R.F. \& ZILBERSTEIN, B. Óxido nítrico: 0 simples mensageiro percorrendo a complexidade. Metabolismo, síntese e funções. Revista Ass. Méd. Brasil, v. 46 (3), p.265-271, 2000.

GARCÍA-MEDIAVILLA, V.; CRESPO, I.; COLLADO, P. S.; ESTELLER, A.; SÁNCHEZ-CAMPOS, S.; TUÑÓN, M. J.; GONZÁLEZ-GALLEGO, J. The antiinflammatory flavones quercetin and kaempferol cause inhibition of inducible nitric oxide synthase, cyclooxygenase-2 and reactive C-protein, and down-regulation of the nuclear fator kappaB pathway in Chang Liver cells. European Journal of Pharmacology, v. 557, p. 221-229, 2007.

GOKBULUT, A.; OZHAN, O.; SATILMIS, B.; BATCIOGLU, K.; GUNAL, S.; SARER, E. Antioxidant and antimicrobial activities and phenoliccompunds of selected Inula species from Turkey. Natural Product Communications, v. 8, n. 4, p. 475-478, 2013.

GRISHAM, M.B.; GRANGER, D.N.; NEIL, D. \& LEFER, D. J. Modulation of leukocyte-endothelial interactions by reactive metabolites of axygen and nitrogen: relevance to is chemic heart disease. Free Radical Biol. Med., v. 25, p. 404-433, 1998.

GRISHAM, M.B.; JOURD'HEUIL, D. \& WINK, D.A. Physioligical chemistry of nitric oxid and its metabolites: implications of inflammation. Americam Physiological society, v. 0193, p. G315-G321, 1999.

RC: 85294

Disponível em: https://www.nucleodoconhecimento.com.br/quimica/anti-inflamatoria 
GUPTA, R.; LOHANI, M.; ARORA, S.; REHNI, A. K.; CHAUHAN, R. Antiinflammatory activity of extracts and isolated alkaloidal fraction from leaves of Bryophyllum pinnatum. Pharmacology online, v. 2, p. 873- 886, 2010.

KAMBOJ, A.; SALUJA, A. K. Bryophyllum pinnatum (Lam.) Kurz.: Phytochemical and pharmacological profile : A review. Pharmacognosy Review, v.3, n. 6, p. 364-374, 2009.

KUMAR, V. et al. Robbins-Patologia Básica. 8. ed, Rio de Janeiro: ELSEVIER. 2008.

LIMA, D. Manual de farmacologia clínica: terpêutica e toxicologia. Rio de Janeiro: Guanabara Koogan, p. 1252, 1993.

LIMA, K.V.B. Estudo da atividade antiinflmatoria do extrato hidroalcoolico de Cissampelos sympodialis Eich (Menispermaceae) em diferentes modelos experimentais. Centro de Ciências da Saúde, João Pessoa, p 14-32, 1999.

MACIEL, M. A. M.; PINTO, C. A.; VEIGA Jr. V. F.; GRYBERG, N. F., ECHEVARRIA, A. Plantas Medicinais: a Necessidade de estudos Multidisciplinares. Quimica nova, v. 25 , n. 3, p. 429- 438, 2002.

MAJAZ, Q.; KHURSHID, M.; NAZIM, S.; RAHIL,K.; SIRAJ, S.; Evaluation of antioxidant activity of Kalanchoe pinnata. International Journal of Research in Ayurveda e Pharmacy, v.2, n.6, p. 1772-1775, 2011.

MELO, M.G.D.; G. A. A. Dória; Serafini, M.R.; Araújo, A. A. S. Valores de referência Hematológicos e Bioquímicos de Ratos (Rattus novergicus linhagem Wistar) provenientes do biotério central da Universidade Federal de Sergipe. Scientia Plena 8, 049903 (2012). 
MONCADA, S.; PALMER, R.M.J.; HiGGS, E.A. Nitric oxide physiology, pathophysiology and pharmacology. Pharmacological Reviews 43, 104-142. (1991)

MOTTA, V.T. Bioquímica clínica para laboratório. Rio de Janeiro:Medbook, 5 ed. 2009.

MUTHU, C.; AYYANAR, M.; RAJA, N,. IGNACIMUTHU, S. Medicinal plants used by traditional healers in Kancheepuram district of Tamil Nadu, India. Journal of Ethnobiology and Ethnomedicine, v. 7, n. 2, p. 43, 2006.

MUTHUIRULAPPAN, S.; RAJENDREN, S. Trend on tradicional system of medicine and modern Ethnopharmacology - Perspective view. International Journal of Research in Pharmaceutical Sciences, v. 4, n. 1, p. 7-11, 2013.

MUZITANO, M. F. Flavonoides de Kalanchoe pinnata (CRASSULACEAE): Avanços na pesquisa da utilização desta espécie medicinal no tratamento da leischmaniose cutânea. Rio de Janeiro, 2006. 186 p. Tese de doutorado apresentada ao Programa de Pós-Graduação em Química de Produtos Naturais, Universidade Federal do Rio de Janeiro, Rio de Janeiro, 2006a.

MUZITANO, M. F.; TINOCO, L. W.; GUETTE, C.; KAISER, C. R.; ROSSIBERGMANN, B.; COSTA, S. S. The antileishmanial activity asssment of unusual flavonoids from Kalanchoe pinnata. Phytochemistry, v. 67, p. 2071-2077, 2006b.

MUZITANO, M. F.; BERGONZI, M. C.; MELO, G. O. D.; LAGE, C. L. S.; BILIA, A. R.; VINCIERI, F. F.; ROSSI-BERGMANN, B.; COSTA, S. S. Influence of cultivation conditions, season of collection and extraction method on the content of antileishmanial 131 flavonoids from Kalanchoe pinnata. Journal of Ethnopharmacology, v. 133, p. 132-137, 2011.

RC: 85294

Disponível em: https://www.nucleodoconhecimento.com.br/quimica/anti-inflamatoria 
NATHAN, C. Points of control in inflammation. Nature, 420: 846-52, 2002.

NAYAK, B.S.; MARSHALL, J.R.; ISITOR, G. Wound healing potential of ethanolic extract of Kalanchoe pinnata Lam. leaf- A preliminary study. Indian Journal of Experimental Biology. v. 48, p. 572-576, 2010.

NIEMEGEERS,C.J.; VERBRUGGEN, F.J.; JANSSEN, P.A. Effect of various drugs on carrgeenan-induced $\mathrm{o}$ edema in the rat hind paw. Journal of Pharmacy na Pharmacology, v.16, p. 810-816, 1964.

OJEWOLE, J. A. O. Antinociceptive, anti-inflammatory and antidiabetic effects of Bryophyllum pinnatum (Crassulaceae) leaf aqueous extract. Journal of Ethnopharmacology, v. 99, p. 13-19, 2005.

OKWU, D. E.; JOSIAH, C. Evaluation of the chemical composition of two Nigerian medicinal plants. African Journal of Biotechnology, v. 5, n. 4, p. 357-361, 2006.

OKWU, D. E.; NNAMDI, F. U. A novel antimicrobial phenanthrene alkaloid from Bryophyllum pinnatum. E-Journal of Chemistry, v. 8, n. 3, p. 1456-1461, 2011.

OKUDAIRA, M.; SCHUWARZ, J. Histoplasma capsulatum infection in rat air pouch. Arch Pathol. 1962-Sep; 74:239-43.

OTUKI, M. F.; VIEIRA-LIMA, F.; MALHEIROS, A.; YUNES, R. A.; CALIXTO, J. B. Topical antiinflammatory effects of the ether extract from Protium kleinii and a-amyrin pentacyclic triterpene. European Journal of Pharmacology, v. 507, p. 253-259, 2005.

PADMJA, S. \& HUIE, R.E. The reaction of nitric oxide with organic peroxyl radicals. Biochem. Biophys. Res. Commum.; v 195, p. 539-544, 1993.

RC: 85294

Disponível em: https://www.nucleodoconhecimento.com.br/quimica/anti-inflamatoria 
POSADA, D.; CRANDALL, K.A.; TEMPLETON, A.R. GeoDis: A program for the Cladistic Nested Analysis of the Geographical Distribution of Genetic Haplotypes. Mol Ecol, 9: 487-488. (2000).

RIBEIRO, R. A.; FLORES, C. A.; CUNHA, F. Q.; FERREIRA, S. H. IL-8 causes in vivo neutrophilmigration by a cell-dependent mechanism. Immunology. 73(4):472-7, 2000

ROBINSON, M.M.; ZHANG, X. The world medicinis situations 2011: tradicional medicines: global situations, issues and challengs. 3 ed. Geneva: World Health Organization, 2011. $12 \quad$ disponível em: http://digicollection.org./hss/documents/s18063en/s18063en.pdf. Acesso em 25 de fevereiro de 2019.

SANTOS, S. D. A.; MELLO, J. C. P. D. Taninos. In: SIMÕES, C.M. O.; SCHENKEL, E. P.; GOSMAN, G.; MELLO, J.C.P.; MENTZ, L.A.; PETROVICK, P. R. Farmacognosia: da planta ao medicamento. $5^{\mathrm{a}} \mathrm{ed}$. rev. ampl. Porto Alegre / Florianópolis: Editora da UFRGS / Editora da UFSC, 2003, p. 615-656.

SALAHDEEN, H. M.; YEMITAN, O. K. Neuropharmacological effects of aqueous leaf extract of Bryophyllum pinnatum in mice. African Journal of Biomedical Research, v.9, n. 2, p. 101-107, 2006.

SARKER, SATYAIJIT D. Química para estudantes de farmácia: química geral, orgânica e de produtos naturais. - [Reimpr.]. - Rio de Janeiro: Guanabara Koogan, 2016.

SCHENKEL, E. P.; GOSMANN, G.; PETROVICK, P. R. Produtos de origem vegetal e o desenvolvimento de medicamentos. In: SIMÕES, C.M. O.; SCHENKEL, E. P.; GOSMAN, G.; MELLO, J.C.P.; MENTZ, L.A.; PETROVICK, P. R. Farmacognosia:

RC: 85294

Disponível em: https://www.nucleodoconhecimento.com.br/quimica/anti-inflamatoria 
da planta ao medicamento. $5^{a}$ ed. rev. ampl. Porto Alegre / Florianópolis: Editora da UFRGS / Editora da UFSC, 2003. p.371-402.

SIDDIQUI, S.; FAIZI, S.; SIDDIQUI, B.S.; SULTANA, N. Triterpenoids and phenanthrenes from leaves of Bryophyllum pinnatum. Phytochemistry, v.28, n.9, p.2433-2438, 1989.

SILVA, M. C.; CARVALHO, J. C. T. Inflamação. In: CARVALHO, J. C. T. Fitoterápicos anti-inflamatórios - Aspectos químicos, farmacológicos e aplicações terapêuticas. Ribeirão preto, SP: Tecmedd, 2004, 480p.

SIMÕES, C. M. O.; SPITZER, V. Óleos Voláteis. In: SIMÕES, C.M. O.; SCHENKEL, E. P.; GOSMAN, G.; MELLO, J.C.P.; MENTZ, L.A.; PETROVICK, P. R. Farmacognosia: da planta ao medicamento. $5^{\mathrm{a}} \mathrm{ed}$. rev. ampl. Porto Alegre / Florianópolis: Editora da UFRGS / Editora da UFSC, 2003, p. 466-496.

SMITH, G. Kalanchoe species poisoning in pets. Veterinary Medicine, p.933936. 2004.Disponível

em:

$<$ http://veterinarymedicine.dvm360.com/vetmed/article/article Detail.jsp?id=132513>. Acesso em: 26 de junho de 2019.

SEDGWICK, A.D.; WILLOUGHBY, D.A. Iniciation of inflammatory response and its prevention. In: Handbook of inflammation. Eds. Bonta, I.L., Bray, M.A.; Parnham, M.J., p. 27-47, New York: Elsevier, 1985.

SOUSA, F. C. F.; MELO, C. T. V.; CITÓ, M. C. O.; FÉLIX, F. H. C.; VASCONCELOS, S. M. M.; FONTELES, M. M. F.; FILHO, J. M. B.; VIANA, G. S. B. Plantas medicinais e seus constituintes bioativos: Uma visão da bioatividade e potenciais benéficos nos distúrbios da ansiedade em modelos animais. Revista Brasileira de Farmacognosia, v. 18, n. 4, p. 642- 654, 2008.

RC: 85294

Disponível em: https://www.nucleodoconhecimento.com.br/quimica/anti-inflamatoria 
STADLER,J.; STEFANOVIC-RACIC.M.; BILLIAR.T.R.; EVANS,T.G. Dowinregulation of nitric oxide biosynthesis by cíclic nucleolidcs. IN:MONCADA,S.,MARLETTA.M.A., HIBBS,J.B.Jr.,HIGGS,E.A. Biology of nilrii- nxide:2. London: Portand Press, 1992.

TATSIMO, S. J. N.; TAMOKOU, J. D.; HAVYARIMANA, L.; CSUPOR, D.; FORGO, P.; HOHMANN, J.; KUIATE, J. R.; TANE, P. Kaempferol rhamnoside derivates from Bryophyllum pinnatum. BioMed Central Research Notes, v. 5 p. 158, 2012.

VINEGAR, R., TRAUX J.F, SELPH J.L. Some quantitative temporal characteristic of carrageenin-induced pleurisy in the rat. Proceedings of the Society for Experimental Biology and Medicine, v.143, p.711-714, 1973.

WILLOUGHBY, D. A. In vivo models of Inflammation. In: WINYARD, P. G.; WILLOUGHBY, D. A. Inflammation protocols, New Jersey: Humana Press, p. 129131, 2003.

WINK, D.A.; COOK, J.A.; KIM, S.; VODOVOTZ,Y.; PACELLI, R.; KIRSHNA, M.C.;RUSSO, A.;MITCHELL, J.B.; JOURD'HEUIL, D.; MILES, A.M. \& GRISHAM, M.B. Superoxide mudales the oxidation and nitrosation of thiols by nitric oxide derived reactive intermediates. J. Biol. Chem., v.272, p.11147,11151, 1997.

WINK, D.A. \& MITCHELV, J.B. The chemical biology of nitric oxide: insights intoregulatory, cytotoxic and cytoproctetive mechanisms of nitric oxide. Free Radic. Biol. Med., v. 25, p.434-456, 1998.

WRIGHT C.V.E SCHNEGELSBERG P De ROBERTIS E.M. XIHbox 8 : A novel Xenopus homeo protein restricted to a narrow band of endoderm. Development. 1989; 105: 787.

Enviado: Novembro, 2020.

RC: 85294

Disponível em: https://www.nucleodoconhecimento.com.br/quimica/anti-inflamatoria 
Aprovado: Maio, 2021. 